\title{
Laccases to take on the challenge of emerging organic contaminants in wastewater
}

\author{
Christoph A. Gasser • Erik M. Ammann • \\ Patrick Shahgaldian • Philippe F.-X. Corvini
}

Received: 14 August 2014 /Revised: 16 October 2014 / Accepted: 17 October 2014 / Published online: 31 October 2014

(C) Springer-Verlag Berlin Heidelberg 2014

\begin{abstract}
The removal of emerging organic contaminants from municipal wastewater poses a major challenge unsatisfactorily addressed by present wastewater treatment processes. Enzymecatalyzed transformation of emerging organic contaminants (EOC) has been proposed as a possible solution to this major environmental issue more than a decade ago. Especially, laccases gained interest in this context in recent years due to their broad substrate range and since they only need molecular oxygen as a cosubstrate. In order to ensure the stability of the enzymes and allow their retention and reuse, either immobilization or insolubilization of the biocatalysts seems to be the prerequisite for continuous wastewater treatment applications. The present review summarizes the research conducted on EOC transformation with laccases and presents an overview of the possible immobilization techniques. The goal is to assess the state of the art and identify the next necessary steps that have to be undertaken in order to implement laccases as a tertiary wastewater treatment process in sewage treatment plants.
\end{abstract}

Keywords Laccase $\cdot$ Wastewater treatment $\cdot$ Emerging organic contaminants $\cdot$ Endocrine-disrupting compounds · Enzyme immobilization

C. A. Gasser • E. M. Ammann • P. F.-X. Corvini $(\triangle)$

Institute for Ecopreneurship, School of Life Sciences, University of Applied Sciences and Arts Northwestern Switzerland,

Gründenstrasse 40, Muttenz CH-4132, Switzerland

e-mail: philippe.corvini@fhnw.ch

P. Shahgaldian

Institute for Chemistry and Bioanalytics, School of Life Sciences, University of Applied Sciences and Arts Northwestern Switzerland, Gründenstrasse 40, Muttenz CH-4132, Switzerland

\section{P. F.-X. Corvini}

State Key Laboratory of Pollution Control and Resource Reuse, School of the Environment, Nanjing University Xianlin Campus, Xianlin Avenue 163, Nanjing 210023, China

\section{Introduction}

Freshwater systems are increasingly contaminated with myriads of industrial and natural chemical compounds (Schwarzenbach et al. 2006). Among them, emerging organic contaminants (EOCs) like pharmaceuticals and other hormonally active chemicals give rise to increasing concerns due to their potential adverse effects on human health and aquatic ecosystems (Cirja et al. 2008; Kuster et al. 2008; Zhang et al. 2011). Particularly, the occurrence and fate of endocrinedisrupting compounds (EDCs), a subgroup of EOCs, have gained increasing interest worldwide due to the ability of this class of compounds to alter endocrine functions at trace concentrations (ng to $\mu \mathrm{g} \mathrm{L}^{-1}$ range) and because of their various detrimental health effects in intact organisms as well as in their offspring (Greim 2004). Wastewater treatment plant (WWTP) effluents have been reported in numerous studies to be major sources of EDC release into the environment (Auriol et al. 2006; González et al. 2007; Stasinakis et al. 2008; SánchezAvila et al. 2009; Ying et al. 2009).

While source control and ban of certain compounds might be expedient ways to limit EOC pollution, the extension of WWTPs by tertiary treatments aimed at removal of these compounds seems necessary in order to appropriately tackle this problem. Harsh physicochemical methods like ozonation, Fenton oxidation, or photocatalytic oxidation are efficient procedures for EOC transformation (reviewed by Mohapatra et al. 2010b). However, they necessitate the addition of catalysts and oxidants that are costly and may lead to secondary pollution (Hu et al. 2002; Korshin et al. 2006). Additionally, various by-products, potentially more toxic than the parent compound itself, might be formed during harsh oxidative treatments (Mohapatra et al. 2010b). Other treatment options proposed involve the adsorption of EOCs, for instance, with powdered activated carbon (PAC) or granulated activated carbon (GAC; Snyder et al. 2007; Cecen and Aktas 2011; 
Margot et al. 2013a; Löwenberg et al. 2014). While these methods do not lead to the formation of undesirable side products and their mechanism of removal is clear, they necessitate the addition of activated carbon leading to increased amounts of sewage sludge. Furthermore, the loading of wastewater effluents with solids, in case of PAC, necessitates an additional filtration step (Rosenstiel and Ort 2008). Moreover, certain compounds like Irgarol, primidone, gabapentin, or diatrizoic acid have a low affinity to adsorb on PAC and are therefore not effectively removed by this treatment option (Margot et al. 2013a).

In the endeavor to find less resource-intensive technologies, enzyme-catalyzed transformation processes for the removal of EOCs have been explored in recent years (Cabana et al. 2007a; Galliker et al. 2010; Majeau et al. 2010; Mohapatra et al. 2010a; Husain and Qayyum 2013). One group of enzymes receiving special attention is that of laccases (benzenediol: oxygen oxidoreductase; EC 1.10.3.2). These enzymes are able to catalyze the oxidation of a wide variety of compounds, i.e., aminophenols, polyphenols, polyamines, and aryl diamines as well as some inorganic ions, and can thereby often transform various EOCs into less reactive derivatives with decreased toxicity (Majeau et al. 2010). Several of these compounds like nonylphenol, pentachlorophenol, or octylphenol have been defined as priority substances by the European Commission in Annex II of an amendment to the Water Framework Directive (Directive 2008/105/EC). Furthermore, substances which may affect endocrine-related functions or have an adverse impact on the oxygen balance of surface waters are indicated to be main pollutants of water bodies in Annex VIII of the Water Framework Directive (Directive 2000/60/EC). Consequently, efforts to limit discharge of such substances to surface waters are increasing in several European countries in order to comply with the environmental quality standards set by the directive.

One drawback of enzymes in dissolved form is that they are inactivated in wastewater over time due to harsh conditions, i.e., unfavorable $\mathrm{pH}$, high salt concentrations, chemical/ biological denaturing agents, or temperature (Majeau et al. 2010; Cabana et al. 2011). In order to overcome this problem, immobilization and insolubilization techniques for laccases have been investigated lately (recently reviewed by Ba et al. 2013) and some techniques were shown to considerably enhance enzymatic stability in wastewater treatment processes (e.g., Gasser et al. 2014). Furthermore, immobilization or insolubilization also facilitates the retention/reuse of the biocatalysts and thereby greatly improves the efficiency of the process (Brady and Jordaan 2009; Corvini and Shahgaldian 2010).

The goal of this review is to critically assess the state of the art as well as the feasibility of a tertiary wastewater treatment process for EOC removal by means of immobilized or insolubilized laccases. To that end, an overview on relevant
EOCs and their reported concentration ranges in wastewater effluents is given. Furthermore, the characteristics of laccases, the reasons for their suitability for wastewater treatment, and different general techniques that have been used to immobilize or insolubilize laccases are discussed. The main section of the review summarizes the findings of studies investigating EOC transformation with laccases, giving an overview on EOC transformation products and reaction mechanisms. Subsequently, early studies that proved the principal feasibility and studies exploring the effectiveness of different laccase mediator systems are briefly reviewed, prior to a summary on recent research dealing with reaction conditions relevant for wastewater treatment, e.g., continuous processes and/or real wastewater matrices.

\section{Emerging organic contaminants in wastewater}

EOCs like pharmaceuticals, personal care products, and a variety of EDCs that are biologically active have been identified at an increasing pace over the last years in relation with advances in analytical techniques (Kuster et al. 2008; Snyder 2008). Numerous studies have been conducted on the occurrence and fate of EOCs in wastewater and surface water over the last decade (reviewed recently by Pal et al. 2010; Lapworth et al. 2012). In order to gain information on the ecotoxicological impacts of EOCs, many toxicity tests on freshwater species like water fleas, algae, mussels, and fish as well as on human embryonic cells have been conducted (Pal et al. 2010; Escher et al. 2011; Martín et al. 2012).

Based on these toxicological studies, predicted no-effect concentration (PNEC) values are calculated in order to estimate the concentration at which a certain compound might become harmful to the environment. These values are often calculated based on no-observed effect concentrations (NOEC) or, if no NOEC is available, they are estimated using other values like effect concentrations (EC), minimal inhibitor concentrations, or toxicity thresholds (Lin et al. 2008). However, the concepts of NOEC and EC values have been heavily criticized (Laskowski 1995; Jager 2011). The main critique is that values obtained by both concepts heavily depend on the applied reaction conditions and exposure times. Since organisms in the environment will most likely face different conditions, the actual EC and NOEC values will differ as well. As Jager phrased it, an EC value provides at best "a ballpark estimate of the concentration range where effects can occur" (Jager 2011). Furthermore, some effects like bioaccumulation, bioconcentration, and biomagnification that might lead to harmful effects only after long exposure times and/or in species of a higher trophic level are not sufficiently taken into account when relying on NOEC or EC for the calculation of PNEC values. Additionally, by only investigating single compounds, the possible adverse effects 
of compound mixtures are also not accounted for. Nevertheless, while imperfect, PNEC values are so far the best estimates on potentially harmful concentrations of contaminants available in literature.

Table 1 summarizes the lowest PNEC values reported for various EOCs as well as the reported concentrations of these compounds in WWTP effluents as well as in rivers or streams. This comparison shows that various EOCs like octyl- and nonylphenols, $17 \beta$-estradiol (E2), diclofenac, gemfibrozil, ibuprofen, mefenamic acid, naproxen, sulfamethoxazole, triclosan, and bisphenol A (BPA) are found at potentially harmful concentrations in the effluents of WWTPs and in the environment. Furthermore, considerable variations of effluent concentrations exist between different WWTPs, likely due to differences in the regional usage of the compounds, presence of chemical production plants, and removal efficiencies of WWTPs. Not included in Table 1 are hospital wastewaters, also a major source of EOC release into the environment. EOC concentrations in hospital wastewaters are sometimes considerably higher than in municipal wastewaters, e.g., the analgesic ibuprofen was detected at nearly $730 \mathrm{nM}$ in hospital wastewater (Gómez et al. 2006), while concentrations reported for municipal WWTP effluents vary between 0.05 and 132 nM (Ashton et al. 2004; Kim et al. 2007).

The occurrence of EOCs at potentially harmful concentrations calls for their removal during wastewater treatment. Therefore, tertiary wastewater treatment processes that are able to transform/remove compounds present at very low concentrations $(\sim 0.01-150 \mathrm{nM})$ are of particular interest. Since many EOCs possess a structure prone to oxidation by oxidative enzymes, one treatment option might be to employ such enzymes, i.e., laccases, in order to oxidize EOCs before their release into the environment.

\section{Laccases}

In nature, laccases are produced by various plants, insects, bacteria, and fungi (Giardina et al. 2010). Among them, fungal laccases have attracted much attention due to their low substrate specificity and their ability to transform various compounds like aminophenols, polyphenols, polyamines, and aryl diamines as well as some inorganic ions. Intracellular and extracellular isozymes have been reported and their molecular weight is in the range of 60 to $70 \mathrm{kDa}$ (Baldrian 2006). However, laccases with considerably lower or higher molecular weights have also been described, such as a laccase from Phanerochaete chrysosporium, $47 \mathrm{kDa}$ (Srinivasan et al. 1995), or from Podospora anserina, $390 \mathrm{kDa}$ (Minuth et al. 1978).

Laccases are multicopper oxidases containing at least one but frequently four copper atoms (Ba et al. 2013). Usually, the four copper atoms are of three different types, type 1 (T1 one
$\mathrm{Cu}$ atom), type 2 (T2 one $\mathrm{Cu}$ atom), and type 3 (T3 two $\mathrm{Cu}$ atoms) (Wong 2009). T1 is the primary electron acceptor where the substrate is oxidized by a one-electron reaction. The redox potential of the T1 copper has been determined for various laccases and can differ substantially between laccases from different sources. Generally, the redox potential of fungal laccases is considerably higher (between 0.7 and $0.8 \mathrm{~V}$ ) than the redox potential of plant laccases (between 0.4 and $0.5 \mathrm{~V}$ ) (Reinhammar and Vänngåd 1971; Xu et al. 1996; Piontek et al. 2002). T2 and T3 form a trinuclear cluster. At this site, molecular oxygen is reduced to water by accepting electrons that are first transferred from the $\mathrm{T} 1$ site to the T2/T3 trinuclear site (Wong 2009). Hence, laccases have been described to function similarly to batteries by storing electrons from several oxidation reactions in the trinuclear site before they reduce molecular oxygen (Kunamneni et al. 2007). In the overall reaction, four substrate molecules are oxidized while one oxygen molecule is reduced to two molecules of water (Solomon et al. 2001). During such a substrate oxidation, unstable free radicals are often formed (Kunamneni et al. 2007). Hence, the initial product may undergo further reactions such as a second enzyme-catalyzed oxidation or nonenzymatic reactions like covalent coupling to form dimers, oligomers, and polymers through $\mathrm{C}-\mathrm{C}, \mathrm{C}-\mathrm{O}$, and $\mathrm{C}-\mathrm{N}$ bonds (Claus 2003, 2004); aromatic ring cleavage (Kawai et al. 1988; Durán and Esposito 2000); or depolymerization of complex polymers through cleavage of covalent bonds (mostly alkyl-aryl bonds) that can lead to the release of monomers (Thurston 1994; Breen and Singleton 1999).

The $\mathrm{pH}$ optimal range for laccase activity strongly depends on the substrate (Kunamneni et al. 2007). For substrates like phenols or anilines that undergo $\mathrm{H}^{+}$dissociation, laccases usually show a bell-shaped $\mathrm{pH}$ activity profile with optimal pH between 5 and 7 (Xu et al. 2007). This is due to two opposing effects: On the one hand, increasing $\mathrm{pH}$ leads to decreasing redox potential of these substrates due to the release of $\mathrm{H}^{+}$(Xu et al. 2007). Consequently, the redox potential difference with laccases increases which leads to improved oxidation of the substrate (Xu et al. 2007). On the other hand, increasing $\mathrm{pH}$ inhibits laccase since binding of $\mathrm{OH}^{-}$on the $\mathrm{T} 2 /$ T3 copper disturbs the internal electron transfer between the T1 and T2/T3 sites of the enzyme (Kunamneni et al. 2007). Furthermore, the isoelectric points (pI) of laccases are typically around 4 ranging from 2.6 to 6.9 (Baldrian 2006) and the optimum temperatures have been reported to range from 20 to $85^{\circ} \mathrm{C}$ depending on the laccase (Gasser et al. 2012).

Laccases alone are basically capable of oxidizing substrates with hydroquinone-like characteristics, but high redox potential fungal laccases can even oxidize monophenols and also, in a few cases, non-phenolic substrates like ascorbic acid (Mayer and Staples 2002; Kudanga et al. 2011). However, they are unable to directly catalyze the oxidation of substrates with significantly higher redox potentials compared to the redox 


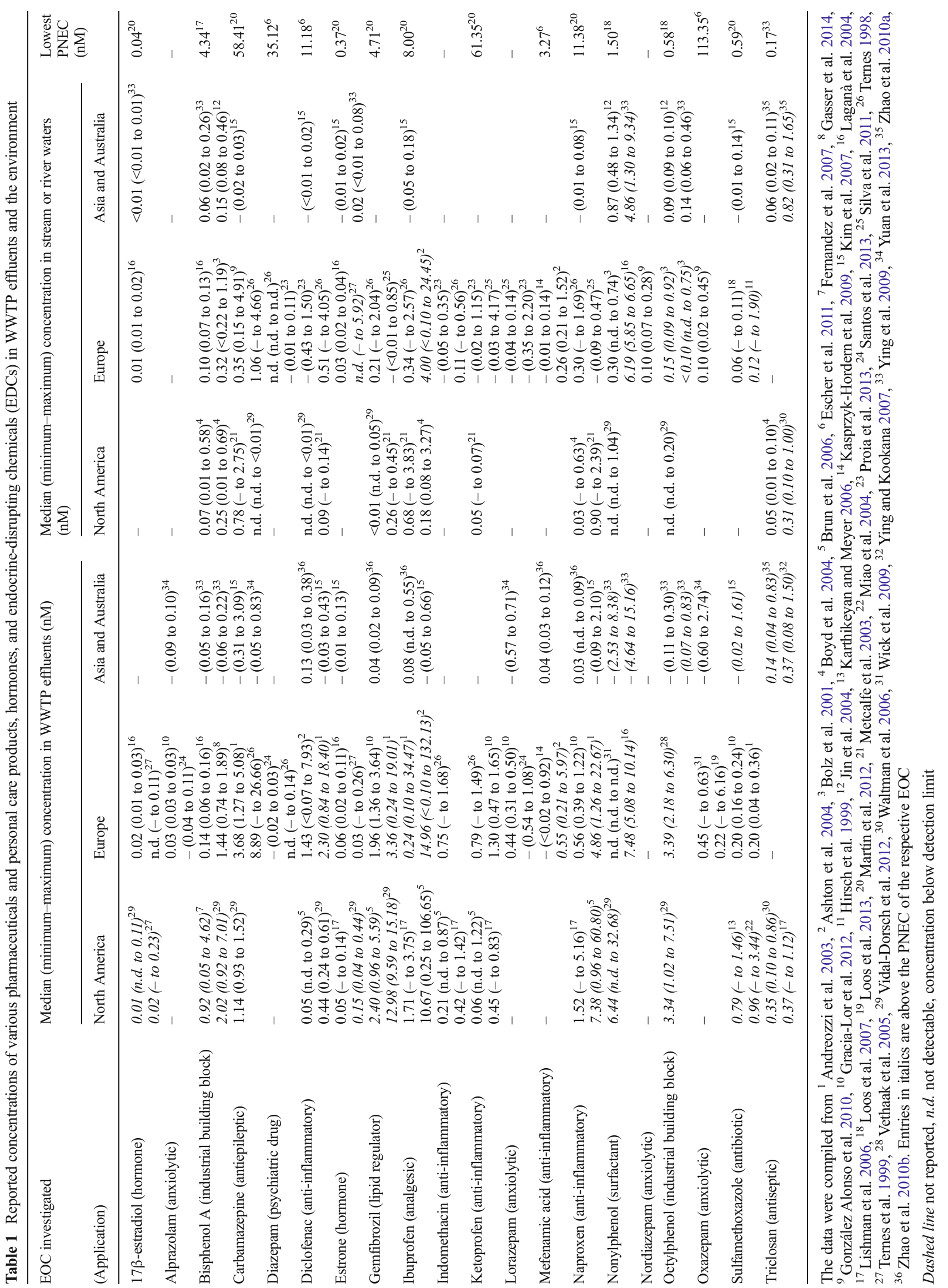


potential of the T1 copper (Morozova et al. 2007). Furthermore, they are unable to catalyze the oxidation of some substrates due to steric hindrance issues (Kudanga et al. 2011). Such compounds can still be targeted by employing small mediators that can be oxidized to radicals by laccases (Morozova et al. 2007; Cañas and Camarero 2010; Kudanga et al. 2011). Basically, any small compound that can be oxidized to a radical by laccase can be employed as redox mediator. In the context of municipal wastewater treatment, it is questionable whether redox mediators should be applied since they potentially lead to secondary pollution of the wastewater and would considerably increase treatment costs. However, compounds already present in wastewater might act as laccase redox mediators or cross-linking between formed radicals and other compounds might occur and lead to larger molecules more prone to precipitation. Such interactions between various laccase substrates were shown by a study investigating the removal of diclofenac, BPA, and $17 \alpha-$ ethinylestradiol (EE2) alone and in mixture using laccase from Coriolopsis gallica immobilized on mesoporous silica spheres in aqueous buffer solutions at $\mathrm{pH} 5$ in a continuous stirred tank membrane reactor (Nair et al. 2013). Treating the single EOCs allowed removing more than $95 \%$ of BPA and EE2 and more than $70 \%$ of diclofenac. However, treating the three EOCs in mixture still led to $95 \%$ removal of BPA and EE2 while more than $90 \%$ of diclofenac was removed. The improved diclofenac removal is most likely due to a mediator effect, i.e., BPA and/or EE2 radicals reacting further with diclofenac (Nair et al. 2013). Results of a further study also investigating laccase oxidation of EOC mixtures were in accordance with these findings. Treating diclofenac with laccase from Trametes versicolor for $20 \mathrm{~h}$ at $\mathrm{pH} 7.2$ and $25{ }^{\circ} \mathrm{C}$ in a single-compound solution led to the removal of $25 \%$ of the initially applied diclofenac (Margot et al. 2013b). However, if BPA or mefenamic acid was present in the reaction mixture as well, diclofenac removal increased to 60 and $95 \%$, respectively. These results indicate that either BPA and mefenamic acid radicals produced through laccase oxidation react with diclofenac as mediator or cross-linking between diclofenac and the radicals occurs leading to larger molecules. According to the observations of the authors, cross-linking seems more likely since more precipitates were visible in mixtures (Margot et al. 2013b).

The reason why laccases attracted much interest for biotechnological applications is based on their characteristics, i.e., their broad substrate range and their use of molecular oxygen as electron acceptor (Giardina et al. 2010). Concerning treatment of municipal wastewater, they seem attractive because of their ability to oxidize various EOCs (Aust and Benson 1993; Xu et al. 1996). Furthermore, several studies have shown that the formed transformation products are less toxic than their parent compounds (Ba et al. 2013). This loss in toxicity might be connected to the physical removal of oligomers that are formed after laccase catalysis, provided these oligomers are insoluble and irreversibly polymerized (Cabana et al. 2007b). These oligomers are formed by radical chain reactions after the initial oxidation of EOCs catalyzed by laccases. In addition, bioavailability and therefore biodegradability of some oxidation products are higher than for the respective parent compound, as is the case for 4isopropenylphenol compared to BPA (Husain and Qayyum 2013).

However, the application of laccases in their dissolved form has some major drawbacks, the main one being that enzymes are usually readily inactivated in wastewater. Furthermore, dissolved enzymes can hardly be separated from wastewater and can, therefore, not be reused. For these reasons, immobilization of laccases on various materials has been investigated and it has been shown that, depending on the immobilization method used, the enzymatic stability of laccases was considerably improved and reuse of enzymes was enabled (Ba et al. 2013).

\section{Laccase immobilization}

In general, immobilization methods are developed in order to facilitate enzyme recovery and reusability and to increase enzymatic stability. Enzymes have been immobilized through various methods described in several comprehensive reviews (Durán et al. 2002; Sheldon 2007; Zhou and Hartmann 2012). The immobilization of laccases for the treatment of wastewaters has been recently reviewed by Ba et al. (2013). Basically, three methods can be distinguished, i.e., support or carrier binding, encapsulation or entrapment, and cross-linking (Durán et al. 2002; Sheldon 2007; Ba et al. 2013). Each method possesses specific advantages and disadvantages depending on the targeted application. Carrier binding methods such as physical adsorption and covalent or ionic binding immobilize the enzymes on a support material. Adsorption occurs via electrostatic interactions, van der Waals forces, and even hydrogen bonding between enzymes and carrier surface (Ba et al. 2013).

\section{Covalent immobilization on solid support material}

Concerning laccase immobilization for wastewater treatment, mostly covalent binding on solid support materials has been investigated (Cabana et al. 2009a; Galliker et al. 2010; Zimmermann et al. 2011; Demarche et al. 2012; Hommes et al. 2012; Lloret et al. 2012a, c; Catapane et al. 2013; Nair et al. 2013; Ammann et al. 2014) since this approach typically yields more stable biocatalysts compared to the other binding methods. Stability is a crucial factor if the immobilized enzymes are intended for use in tertiary wastewater treatment processes in which the enzymes are exposed to harsh 
environmental conditions, i.e., high $\mathrm{pH}$ values, turbulent flows, and presence of remaining organic, inorganic, or biological denaturing agents. Regarding methods like carrier binding or encapsulation, the physical bonding is generally insufficient to keep the enzyme fixed to the support or prevent enzyme leakage, while ionic binding is normally stronger (Sheldon 2007). Covalent binding leads in general to an even more stable immobilization of the biocatalysts on the carrier (Sheldon 2007).

Regarding the specific enzymatic activity that can be immobilized on the carriers, the specific surface area of the support material seems to be a decisive factor. The same immobilization protocol was used for the covalent immobilization of laccase from Coriolopsis polyzona on spherical silica nanoparticles with a specific surface area of $17.4 \mathrm{~m}^{2} \mathrm{~g}^{-1}$ and to fumed silica nanoparticles (fsNP) with a specific surface area of $\sim 390 \mathrm{~m}^{2} \mathrm{~g}^{-1}$ (Zimmermann et al. 2011). Resulting biocatalysts immobilized on fsNP had a 14.3 times higher specific enzymatic activity than biocatalysts immobilized on spherical silica nanoparticles, demonstrating the importance of a large specific surface area.

The series of reaction steps during enzyme immobilization was investigated in the context of this study as well. In a first approach, the surface of the fsNP was modified with 3aminopropyltriethoxysilane (APTES). In a second step, the cross-linker was added and allowed to react with the amino group on the surface of the modified fsNP. Excess crosslinkers were removed before; in a third step, the enzymes were added and covalently immobilized on the particle surface. In a second approach, a sorption step was introduced in which the enzymes were allowed to adsorb to the modified particle surface prior to cross-linker addition. The first approach results in covalent immobilization of the enzymes on the particle surface, while the second approach additionally results in intramolecular cross-linking of the enzyme molecules and consequently in the formation of cross-linked enzyme aggregates (CLEAs) on the particle surface. The second approach allowed the immobilization of nearly twice as much enzymatic activity on the fsNP surface. The stability of the two biocatalysts was investigated in buffer solutions at $\mathrm{pH} 7$ over 1 month. No considerable differences in stability could be observed. After 32 days, the biocatalysts retained $63.3 \pm 1.3$ and $57.0 \pm 2.2 \%$ of their initial activity for biocatalysts produced by the first and second approaches, respectively. Immobilization increased enzymatic stability considerably since only $20.1 \pm 1.7 \%$ of the initial activity of dissolved laccase remained after 29 days. Stability tests in WWTP effluent at $\mathrm{pH} 8.2$ were conducted with biocatalysts produced with the second immobilization approach, with dissolved enzymes, and enzymes only adsorbed on fsNP. While the covalently immobilized enzymes still retained around $80 \%$ of their initial enzymatic activity after 32 days, the dissolved and the adsorbed enzymes lost most of their activity within the first 10 days (Zimmermann et al. 2011).

A study investigating two similar approaches as in the study by Zimmermann et al. (2011) for the immobilization of laccase from $C$. polyzona on diatomaceous earth support Celite ${ }^{\circledR} \mathrm{R}-633$ yielded different results regarding the reaction sequence leading to biocatalysts with the highest specific enzymatic activity (Cabana et al. 2009a). Besides testing two different series of reaction steps, the effects of two different cross-linkers, i.e., glutaraldehyde and glyoxal, were investigated as well. The first series of reaction steps consisted of surface modification with APTES followed by cross-linker addition before finally applying the enzymes, i.e., the same sequence as used in the first approach by Zimmermann et al. (2011). In the second approach, the cross-linker and the enzymes were added simultaneously after surface activation with APTES, thereby allowing internal cross-linking of enzymes. In contrast to the second approach in the study by Zimmermann et al. (2011), no sorption step was introduced. The biocatalyst produced by the sequential application of glutaraldehyde and enzymes showed the highest activity with respect to a standard substrate, i.e., 2,2'-azino-bis(3ethylbenzthiazoline)-6-sulfonic acid (ABTS). However, the biocatalyst produced by the simultaneous application of the cross-linker and enzyme retained considerably higher percentages of its initial activity after incubation at $\mathrm{pH} 3$ and $40^{\circ} \mathrm{C}$ for $24 \mathrm{~h}$ compared to the biocatalyst produced using the sequential method. Furthermore, the biocatalyst produced using the simultaneous approach and glutaraldehyde retained more activity compared to the biocatalyst produced by the sequential method using glutaraldehyde after $30 \mathrm{~min}$ of incubation with several denaturants, i.e., methanol, acetone, ethylenediaminetetraacetic acid (EDTA), and $\mathrm{CaCl}_{2}$ at $\mathrm{pH} 3$ and room temperature (Cabana et al. 2009a). These results clearly indicate that the internal cross-linking of the enzymes considerably increased their stability which is in accordance with the observed stability increases of CLEAs. However, the enzymatic activity immobilized per weight of support material was low compared to the enzymatic activity immobilized in other studies using different support materials like $\gamma-\mathrm{Al}_{2} \mathrm{O}_{3}$ (Kandelbauer et al. 2004) or fsNP (Zimmermann et al. 2011 ), i.e., the specific activity was $0.27,13.26$, and $2920 \mathrm{U} \mathrm{g}^{-1}$ for Celite ${ }^{\circledR} \mathrm{R}-633, \gamma-\mathrm{Al}_{2} \mathrm{O}_{3}$, and fsNP, respectively. As discussed above, this difference was most likely due to the low specific surface area of only $1.3 \mathrm{~m}^{2} \mathrm{~g}^{-1}$ for Celite ${ }^{\circledR}$ $\mathrm{R}-633$ compared to the considerably higher specific surface areas of 31 and $\sim 390 \mathrm{~m}^{2} \mathrm{~g}^{-1}$ for $\gamma-\mathrm{Al}_{2} \mathrm{O}_{3}$ and fsNP, respectively. It is not entirely clear why the two studies obtained different results regarding the sequence of reaction steps leading to biocatalysts with the highest specific enzymatic activities. It can be speculated that introducing a sorption step prior to cross-linker addition leads to enzymes already close to the support material, making immobilization on the support 
material more likely, while the simultaneous addition of crosslinker and enzyme can lead to the formation of CLEAs which are not immobilized on the carrier.

Next to the often reported favorable effects on enzymatic stability through enzyme immobilization on solid carriers (Cabana et al. 2009a; Zimmermann et al. 2011; Hommes et al. 2012; Nair et al. 2013; Ammann et al. 2014), there are also shortcomings to the resulting biocatalysts. For example, reduced activity towards certain substrates in comparison to dissolved enzymes is sometimes reported and attributed to diffusional limitations of substrates (Hommes et al. 2012). Furthermore, suspended solids or organic matter present in wastewater might adsorb on the carrier surfaces ((bio)fouling), reducing accessibility of the active sites of the biocatalysts for the targeted compounds. In case of particles, it might also intensify aggregation and settling of support particles harboring the immobilized biocatalysts, making proper mixing more laborious.

\section{Encapsulation}

A further immobilization method, known as encapsulation (entrapment), occurs via inclusion of enzymes inside a polymer network (gel lattice) such as organic polymer, silica solgel, or a membrane device such as a hollow fiber or a microcapsule in order to preserve the enzyme's three-dimensional structure (Sheldon 2007).

Literature concerning laccase encapsulation for oxidation of EOCs is rather scarce. Even though stability towards $\mathrm{pH}$, temperature, and several inactivating agents, i.e., $\mathrm{NaN}_{3}$, $\mathrm{ZnCl}_{2}, \mathrm{CoCl}_{2}, \mathrm{CaCl}_{2}$, methanol, and acetone, could be enhanced by Myceliophthora thermophila encapsulation in a sol-gel matrix (Lloret et al. 2011), the achieved removal of the EOCs estrone (E1), E2, and EE2 was lower (i.e., 55, 75, and $60 \%$, respectively) compared to achieved removals with the same laccase immobilized on Eupergit support (removal of up to 65,80 , and $80 \%$ for E1, E2, and EE2, respectively; Lloret et al. 2012a, c) or applied in dissolved form (removal of up to 98,97 , and $99 \%$ for E1, E2, and EE2, respectively; Lloret et al. 2012b, 2013a, b). The lower removal by encapsulated laccases might be due to diffusion limitations leading to slower reaction kinetics commonly reported for encapsulated enzymes (Pierre 2004). Furthermore, encapsulationinduced aggregation or unfolding of proteins is a major issue in the preparation of such biocatalysts, rendering the choice of a suitable methodology particularly important (Castellanos et al. 2002).

\section{CLEAs}

Another immobilization approach uses protein cross-linking by covalently binding functional groups (e.g., amine groups, carboxylic groups) of different enzyme molecules using a bi- or multi-functional reagent in the absence of a carrier (Ba et al. 2013), which is the main advantage of this method. Consequently, the specific activity of the catalysts can be expected to be higher compared to catalysts immobilized on solid supports assuming that cross-linking does not severely affect the catalytic activity of the enzymes. Several protein cross-linking methods exist such as cross-linking the enzymes in solution (cross-linked enzymes, CLEs), spray-drying the biocatalysts prior to immobilization (cross-linked spray dry, CLSD), laborious cross-linking of highly pure enzyme microcrystals (cross-linked enzyme crystals, CLECs), or the formation of enzyme aggregates using raw enzymes (cross-linked enzyme aggregates, CLEAs) (Sheldon 2007; Ba et al. 2013). Biocatalysts such as CLEs and CLSD have generally low mechanical stability, which is not the case for CLECs and CLEAs (Sheldon 2007; Ba et al. 2013). However, production of CLECs is much more laborious than for CLEAs, leading to increased costs. Consequently, immobilization of laccases as CLEAs seems the most attractive carrier-free cross-linking method with regard to a possible application in wastewater treatment. CLEAs from laccase from C. polyzona have been produced and characterized regarding their stability towards several inactivating agents, i.e., EDTA, $\mathrm{NaN}_{3}$, methanol, acetone, $\mathrm{ZnCl}_{2}, \mathrm{CoCl}_{2}$, and $\mathrm{CaCl}_{2}$ (Cabana et al. 2007c). As a result, stability was increased towards EDTA, $\mathrm{NaN}_{3}$, methanol, and acetone compared to dissolved enzyme. However, no considerable difference between free and immobilized enzyme stability towards the chaotropic salts was observed. Consequently, the structural alteration of the catalytic site known to occur through azide binding (Battistuzzi et al. 2003) was decreased and the stability against organic solvents was increased due to immobilization. Furthermore, the mass transfer of the chelator EDTA might have been hindered by the amorphous structure of the CLEAs (Cabana et al. 2007b). However, results indicate that the small salts could easily penetrate the CLEA structure since there was no considerable difference in stability between the CLEAs and the dissolved laccase (Cabana et al. 2007b).

As already pointed out by others (Sheldon 2007), direct comparison of the different immobilization methods based on literature is difficult. Most studies compare the performances of immobilized/insolubilized enzymes prepared by only one technique with the free enzyme. However, every enzyme responds uniquely to an immobilization method, and for proper comparison, several parameters would have to be determined, like enzyme pH optimum, immobilization efficiency, enzyme activity, and enzyme stability (Jochems et al. 2011). Moreover, some of the changes in enzymatic stability and activity that are observed might not be due to conformational changes of the enzyme but due to differences in the vicinity of the immobilized/insolubilized biocatalyst compared to the bulk environment (De Maio et al. 2003). Since substrate oxidation to radical species takes place at the active site of 
the enzymes, the radical concentration in proximity of the immobilized biocatalysts might be higher than in bulk solution. Therefore, the occurrence of radical chain reactions might be increased in reactions using immobilized enzymes compared to reactions using dissolved enzymes.

\section{EOC transformation}

Treatment of industrial wastewaters employing phenol oxidases, i.e., peroxidases, tyrosinases, or laccases, has been suggested since the 1980s (Klibanov et al. 1980). Subsequently, many studies reported on the use of these enzymes in soluble form for the treatment of effluents from paper and pulp, dye and printing, and olive oil mill industry, as well as distillery wastewaters (reviewed by Strong and Claus 2011). In the same decade, the potential of this procedure was also recognized for the transformation of trace organic compounds in drinking water (Maloney et al. 1986). Therefore, interest in municipal wastewater treatment with phenol oxidases was rising with the increasing concern over EOCs released through WWTP effluents. Laccases seem to be the most promising phenol oxidases for such an application since they have a broader substrate range than tyrosinases and, unlike peroxidases, do not need hydrogen peroxide as cosubstrate but only molecular oxygen (Strong and Claus 2011).

\section{EOC transformation products}

Transformation products after laccase treatment of several EOCs were frequently elucidated in response to an increasing demand for ecotoxicological assessment of novel technologies. One good example is BPA, an EDC that is used in the production of polycarbonates and found in environmentally relevant concentrations in WWTP effluents (see Table 1). It was demonstrated that laccase from Trametes villosa is able to polymerize BPA to higher molecular weight compounds and that transformation of BPA can also lead to the formation of 4isopropenylphenol (Fukuda et al. 2001; Uchida et al. 2001). Furthermore, it was shown that this treatment removes the estrogen activity of BPA (Fukuda et al. 2004). Similar transformation products, i.e., phenol, 4-isopropenylphenol, and BPA polymers, were also reported using laccase from C. polyzona immobilized on silica nanoparticles (Galliker et al. 2010). Additionally, laccase from T. versicolor was shown to remove the estrogenic activities of BPA as well as nonylphenol, a degradation product of non-ionic surfactants, most likely through the formation of oligomers (Tsutsumi et al. 2001).

In addition to BPA and nonylphenol, Cabana and coworkers also investigated the transformation of triclosan, an antimicrobial agent, using laccase from C. polyzona (Cabana et al. 2007a, 2009a, b). They showed that the biocatalytic treatment of these substances led to high molecular weight metabolites, and they were able to identify di-, tri-, and tetramers of all three compounds as well as pentamers of nonylphenol (Cabana et al. 2007a). Furthermore, they showed that the transformation of nonylphenol and BPA correlated with the elimination of estrogenic activity (Cabana et al. 2007a). Formation of di- and trimers from triclosan was also identified after treatment with laccase from Ganoderma lucidum (Murugesan et al. 2010). Applying 1hydroxybenzotriazole or syringaldehyde as laccase mediators also led to the formation of breakdown products with lower molecular weight than triclosan. Some compounds were identified as 2,4-dichlorophenol (2,4-DCP), dechlorinated forms of 2,4-DCP, and 2-chlorohydroquinone (Murugesan et al. 2010). Therefore, the results of this study suggested that triclosan was removed by means of laccase-catalyzed reactions, on the one hand, through oligomerization in the absence of redox mediators and, on the other hand, through ether bond cleavage followed by dechlorination in the presence of redox mediators (Murugesan et al. 2010). Oligomer formation of triclosan was also demonstrated through treatment with laccase from T. versicolor (Cabana et al. 2011). In addition to different oligomers of triclosan, the authors also identified triclosan molecules which had lost one chlorine atom as well as dechlorinated triclosan di- and trimers (Cabana et al. 2011). It was suggested that the dechlorination of triclosan through laccase treatment be the result of the formation of a phenoxy radical and a subsequent nucleophilic substitution, a reaction mechanism that has been proposed before for laccasecatalyzed oxidation of other chlorinated compounds like tetrachloroguaiacol (Iimura et al. 1996). The formation of dechlorinated oligomers on the other hand is suggested to result from oxidative coupling reactions of the radicals (Cabana et al. 2011) as was shown previously for chlorophenols (Dec et al. 2003).

Auriol and coworkers investigated the laccase-catalyzed oxidation of natural (E1, E2, and estriol (E3)) as well as one synthetic estrogen (EE2) using T. versicolor laccase (Auriol et al. 2007, 2008). The authors showed that the estrogenic activity of these compounds was completely removed from phosphate buffer solutions (Auriol et al. 2007, 2008). Furthermore, estrogenic activity was removed completely from municipal WWTP effluent samples through treatment with the same laccase (Auriol et al. 2007, 2008). In several studies, Lloret and coworkers further investigated the oxidation of estrogens (E1, E2, and EE2) using M. thermophila laccase (Lloret et al. 2010, 2011, 2012a, b, c, 2013a, b). Next to testing various reaction conditions and reactor designs, reaction products of the estrogens were identified. Formation of di- and trimers of the estrogens suggested elimination through radical coupling reactions (Lloret et al. 2013b). 
However, after transformation of E1 and E2, species with lower molecular weight than the parent compounds were identified in addition to di- and trimers, showing that additional reactions occurred (Lloret et al. 2013b).

Transformation of diclofenac to 4-(2,6dichlorophenylamino)-1,3-benzenedimethanol was demonstrated by employing laccase from $T$. versicolor (MarcoUrrea et al. 2010). A study of transformation products from diclofenac by size exclusion chromatography after treatment with a laccase from a Thielavia genus revealed that various oligomers were produced (Hommes et al. 2013). Despite that the structure of these oligomers was not elucidated, the size exclusion chromatograms suggested that di-, tri-, tetra-, and pentamers of diclofenac were formed.

Overall, studies on transformation products of EOCs through laccase treatment suggest that treatment of wastewater with laccase has the potential to lower wastewater toxicity. The produced oligomers are often insoluble in aqueous solution and can therefore be removed easily. Furthermore, laccase transformation of EOCs can lead to dehalogenation making thereby the compounds less toxic. In addition, some products formed are more biodegradable than the parent compounds themselves (e.g., 4-isopropenylphenol compared to BPA) and therefore of less environmental concern (Husain and Qayyum 2013).

To date, only few studies report on transformation products of EOCs after laccase treatment performed under conditions close to those found in WWTP effluents, i.e., neutral to alkaline $\mathrm{pH}$, mixture of EOCs present at low concentrations, and presence of organic and inorganic compounds and of microorganisms. In a study already mentioned above, dimers of E2 and EE2 were identified in the permeate of an enzymatic membrane reactor after laccase treatment of WWTP effluent containing E2 and EE2 at concentrations of 1.06 and $2.50 \mathrm{pM}$, respectively (Lloret et al. 2013b). These results indicate that laccase-catalyzed radical coupling reactions occurred even at such low concentrations, although the authors point out that other reaction mechanisms cannot be completely excluded (Lloret et al. 2013b). Another study has shown the formation of a more polar transformation product of BPA using laccase from a Thielavia genus in an experiment in which radioactively labeled BPA was spiked at environmentally relevant concentrations $(\sim 0.35 \mathrm{nM})$ to WWTP effluent (Hommes et al. 2012). However, the chemical structure of this transformation product was not further elucidated.

Other experiments with the goal to identify laccase transformation products of EOCs were usually performed by applying substantially higher EOC concentrations $(17 \mu \mathrm{M}-$ $10 \mathrm{mM}$ ) compared to concentrations actually measured in WWTP effluents ( 0.01-150 nM). The probability of oligomer formation is dependent on parent compound concentration and on the organic matrix of wastewater. In fact, organic compounds in WWTP effluent can also react/polymerize with the radicals produced by laccase. As a consequence, a wide range of complex transformation products can occur, i.e., $\mathrm{EOC}_{x}-\mathrm{EOC}_{x}$ oligomers, EOC $x$-EOC $y$ oligomers, EOCorganic matrix conjugates, partial degradation products e.g., isopropylphenol from BPA, etc. Except $\mathrm{EOC}_{x}-\mathrm{EOC}_{x}$ oligomers and partial degradation products, transformation products formed in real wastewater cannot occur in experiments making use of single compounds. Complementarily to the deployment of sophisticated analytical techniques and the application of radiolabeled compounds, the best way to assess the effect of laccase treatment on WWTP effluents might be to implement directed analysis approaches. To this end, bioassays must be sensitive enough to sense transformation products of EOCs at trace concentrations usually found in WWTP effluents.

During laccase treatment, high molecular weight polymerization products might be more effectively retained in reactors compared to their parent compounds since they might be less hydrophilic. Consequently, they might more readily adsorb on the carrier material of the biocatalysts, on reactor walls, or on solids present in wastewater, or they might be removed through retention or adsorption on the membranes. In general, increasing surface areas of carrier materials for enzyme immobilization might lead to increased adsorption and, thereby, removal of the higher molecular weight products. Regarding carrier porosity, smaller pores leading to higher surface areas would in general lead to higher adsorption. However, pores smaller than the enzymes that are immobilized (laccases have usually a size between 5 and $15 \mathrm{~nm}$ (Molitoris et al. 1972)) might be blocked through the biocatalysts and would, therefore, no longer be accessible for products. Influence on enzymatic activity of adsorption of products on carrier materials would have to be further investigated. However, the influence of adsorption of solids or dissolved biopolymers already present in WWTP effluents is most likely higher. Applied membranes will presumably have too high cutoffs to directly retain most polymerization products. The lowest cutoff applied in reviewed studies was $10 \mathrm{kDa}$ allowing retaining dissolved enzymes in enzymatic membrane reactors (Lloret et al. 2013b). Therefore, it has to be expected that some transformation products are released into the environment.

The fate of the released transformation products is associated with some uncertainties due to little information available on actually occurring transformation products under real conditions in organic matrix-containing wastewater. Assuming that higher molecular weight transformation products are in general less hydrophilic than their parent compounds, adsorption of products to solids would be more likely. Therefore, these products would be less bioavailable for aquatic organisms. Deposition of the suspended solids would then lead to deposition of the reaction products in river beds and lakes. Since the concentrations of the targeted substances are very low, it can also be assumed that the concentrations of 
polymerization products would be low. Nonetheless, accumulation of such products in treated-effluent-receiving water bodies cannot be totally excluded. Possible adverse impacts on ecosystems of accumulated products would need to be further investigated. However, it seems unlikely that these impacts are more harmful than those of the water-soluble parent compounds which are much more readily bioavailable.

\section{EOC transformation studies}

A multitude of different reactor designs, laccases, and immobilization methods have been studied so far and, in some cases, optimized for the transformation of EOCs. These studies range from simple batch experiments to continuous treatment in membrane or fixed bed reactors, and from dissolved, over encapsulated to covalently immobilized enzymes. While most of the studies were conducted at lab scale, there are also reports on first trials for wastewater treatment at pilot scale. The following section gives an overview on the research investigating EOC transformation by laccases, shortly mentioning primary batch experiments and then discussing publications investigating reaction conditions closer to real applications, i.e., continuous processes and processes applied to real WWTP effluents, before finally summarizing some recent studies exploring new approaches aimed at improving enzymatic EOC removal.

\section{Primary batch studies}

First trials conducted in batch mode for the removal of the EDCs nonylphenol and BPA with oxidative enzymes using laccase from $T$. versicolor or $T$. villosa or manganese peroxidase from $P$. chrysosporium showed that the estrogenic activity of both compounds could be completely removed by these enzymes (Fukuda et al. 2001, 2004; Tsutsumi et al. 2001; Uchida et al. 2001). However, applied EDC concentrations, $\mathrm{pH}$ values, and temperatures in these reactions differed considerably from what can be expected in WWTP effluents, i.e., EDC concentrations and temperatures were higher, ranging from 0.22 to $1.1 \mathrm{mM}$ and from 30 to $60{ }^{\circ} \mathrm{C}$, respectively, and $\mathrm{pH}$ values were lower, ranging from 4.5 to 6 . Therefore, while results of these studies suggest that EOC transformation by laccases is in principle possible and leads to detoxification, they seem not directly transposable to WWTP effluent conditions.

\section{Laccase mediator systems}

Laccases are able to oxidize small chemical compounds leading to radical formation (Cañas and Camarero 2010). These radicals can act as redox mediators oxidizing compounds that might otherwise not be oxidized by laccase, thus broadening their substrate range. Consequently, several studies investigated the possibility to use laccase mediator systems in batch reactions in order to increase the efficiency of laccasecatalyzed EOC transformation (Kim and Nicell 2006; Murugesan et al. 2010; Tran et al. 2010; OstadhadiDehkordi et al. 2012; Weng et al. 2012; Lloret et al. 2013c). As in the studies mentioned above, EOC concentration, $\mathrm{pH}$, and temperature differed considerably from what can be expected in WWTP effluents.

The transformation of triclosan with various potential laccase mediators was investigated with laccase from T. versicolor (Kim and Nicell 2006) and G. lucidum (Murugesan et al. 2010). The application of a mediator to pollutant ratio of 1:1 only showed a considerable positive effect for the mediator ABTS (Kim and Nicell 2006). Triclosan was completely removed within 30 min using ABTS. However, tests showed that while the relative toxicity of the reaction mixture could be decreased to 0.21 when triclosan was treated with laccase alone, it increased to 120 when ABTS was used as mediator, likely due to the presence of reactive radicals generated from ABTS (Kim and Nicell 2006). Employing a mediator to pollutant ratio of $5: 1$, at a mediator concentration of $1 \mathrm{mM}$, led to considerably better removal using the mediators syringaldehyde or 1 hydroxybenzotriazole compared to only applying the enzyme in the absence of a mediator (Murugesan et al. 2010). Using ABTS also increased triclosan removal compared to the reaction without a mediator. However, the increase was not statistically significant. Addition of all other tested potential mediators, i.e., acetovanillone, vanillin, $p$-coumaric acid, 2,4dimethoxyphenol, and guaiacol, led to decreased triclosan removal (Murugesan et al. 2010). Further studies investigating the transformation of a broader range of EOCs by several laccase mediator systems led to similar results. Clofibric acid, gemfibrozil, ibuprofen, fenoprofen, ketoprofen, naproxen, indomethacin, propyphenazone, and carbamazepine removal could be considerably improved by the application of ABTS or 1-hydroxybenzotriazole at a concentration of $1 \mathrm{mM}$ (Tran et al. 2010). Furthermore, the benzodiazepines alprazolam, oxazepam, nitrazepam, and diazepam were removed more efficiently using $2 \mathrm{mM}$ 1-hydroxybenzotriazole, ABTS, 2,6dimethoxyphenol, or vanillic acid (Ostadhadi-Dehkordi et al. 2012), whereas complete removal of the sulfonamide antibiotics sulfadimethoxine and sulfamonomethoxine was achieved by $1 \mathrm{mM}$ ABTS or violuric acid (Weng et al. 2012). A further study investigated removal of diclofenac and naproxen using 1-hydroxybenzotriazole or syringaldehyde as mediator at a concentration of $1 \mathrm{mM}$ at pH 4 and 7 (Lloret et al. 2013c). Applying 1hydroxybenzotriazole as mediator, 94 and $70 \%$ of naproxen could be removed at $\mathrm{pH} 4$ and 7, respectively, after $24 \mathrm{~h}$ while no naproxen removal was observed without a mediator and only slight removal $(<10 \%)$ was observed using syringaldehyde at $\mathrm{pH} 4$. Complete diclofenac removal could 
be achieved at $\mathrm{pH} 4$ after $4,0.5$, and $2 \mathrm{~h}$ using no mediator, 1hydroxybenzotriazole, and syringaldehyde, respectively. At $\mathrm{pH} 7,27,98$, and $50 \%$ diclofenac were removed after $24 \mathrm{~h}$ of treatment using no mediator, 1-hydroxybenzotriazole, and syringaldehyde, respectively (Lloret et al. 2013c).

The results of all these studies indicate that laccase mediators would have to be applied at rather high concentrations, i.e., in the range of millimolar, in order to have a positive effect on EOC transformation, considerably increasing treatment costs. Furthermore, the presence of mediators might even increase the toxicity of WWTP effluents, as shown for ABTS and syringaldehyde (Kim and Nicell 2006; Nguyen et al. 2014), rendering thereby the treatment ineffective or even harmful. Hence, applying laccase mediator systems for wastewater treatment seems unattractive.

\section{Towards application—using immobilized enzymes in continuous processes}

While batch experiments are convenient experimental setups for assessing the feasibility of the technology and the reaction mechanisms underlying the laccase-catalyzed transformation of EOCs, application of the enzymes in tertiary wastewater treatment will, apart from a few exceptions such as sequencing batch reactors, mostly occur in a continuous process. This necessitates that enzymes are retained in the reactor, since continuous addition of enzymes would most likely lead to uncompetitive treatment costs. Furthermore, the direct release of the enzymes into the environment also poses potential risks. Next to the increase of the chemical oxygen demand going along with the release of additional proteins, the laccases might also have an influence on the ecotoxicity of WWTP effluents. As discussed above, enzyme immobilization is a feasible option to retain and reuse the enzymes. As a consequence, several studies investigated the immobilization of laccases and applied the resulting biocatalysts in continuously operated systems for the transformation of EOCs.

For instance, different immobilization techniques and reactor designs for the transformation of nonylphenol (as technical mixture), BPA, and triclosan with laccase from C. polyzona were reported (Cabana et al. 2009a, b). In a first study, laccase from C. polyzona was immobilized on diatomaceous earth support Celite ${ }^{\circledR}$ R-633 as discussed in the "Laccase immobilization" section (Cabana et al. 2009a). The transformation of nonylphenol $(23 \mu \mathrm{M})$, BPA $(22 \mu \mathrm{M})$, and triclosan $(18 \mu \mathrm{M})$ was studied in a packed bed reactor by repeated batch treatments employing the biocatalyst produced by the sequential application of cross-linker and enzyme using glutaraldehyde as cross-linker (Cabana et al. 2009a). Contact time for each reaction was $200 \mathrm{~min}$ and the treatment was conducted at pH 5 and $20{ }^{\circ} \mathrm{C}$. Removal of the investigated EDCs through adsorption on the support material was determined to be in the range of 40 to $60 \%$. Adsorptive removal and enzymatic transformation allowed the complete removal from aqueous solution of all three investigated EDCs in repeated batch mode in five consecutive cycles (Cabana et al. 2009a).

In a further study, the continuous transformation of the same three EDCs in a perfusion basket reactor with a working volume of $331 \mathrm{~mL}$ using insolubilized C. polyzona laccase as CLEAs was investigated (Cabana et al. 2009b). The CLEAs were shown to have a 190 times higher specific enzymatic activity compared to the biocatalyst immobilized on Celite ${ }^{\circledR}$ R-633 used in the previous study, constituting a considerable improvement. One finding of this study was that agitation conditions strongly influence the apparent laccase activity as well as the enzymatic stability. The latter was negatively affected when $102 \mathrm{rpm}$ was exceeded and vortices in the reaction medium were formed. The apparent activity, on the other hand, increased with rising rotational speed most likely due to an increase in the substrate-enzyme collision rate (Cabana et al. 2009b). Since stability of the CLEAs was deemed more important than their activity, rotational speed was kept low, i.e., at $102 \mathrm{rpm}$, so that no vortices were formed. Optimal conditions for the removal of the three EDCs with regard to $\mathrm{pH}$ and temperature were found to be $\mathrm{pH} 4.8,4.7$, and 4.9 and $40.3,48$, and $41.2^{\circ} \mathrm{C}$ for nonylphenol, BPA, and triclosan, respectively. Operating the reactor at $\mathrm{pH} 5$ and room temperature allowed the removal of at least $85 \%$ of the separately tested EDCs using a hydraulic retention time of $5.42 \mathrm{~h}$, whereas EDC inlet concentrations were 23, 22, and $18 \mu \mathrm{M}$ for nonylphenol, BPA, and triclosan, respectively (Cabana et al. 2009b). Under optimized conditions, continuous removal of the different EOCs could be demonstrated using laccases immobilized as CLEAs. However, like in batch experiments discussed above, reaction conditions differed considerably compared to real wastewater conditions in terms of EDC concentrations, $\mathrm{pH}$, temperature, and the presence of other compounds. Therefore, the performance of the CLEAs under realistic conditions should be tested and stability tests over longer time periods in wastewater should be performed in order to assess whether the produced CLEAs are a viable option for application in wastewater treatment and to estimate treatment costs and efficiency.

Another group investigated the covalent immobilization of laccase from $T$. versicolor on a polypropylene membrane, which was subsequently used for the transformation of various phenolic compounds and their derivatives in aqueous solution at $\mathrm{pH} 5.5$ in a bioreactor operated in continuous mode (Georgieva et al. 2010). Compounds were applied at a concentration of $50 \mu \mathrm{M}$ each. The reactor consisted of two halfcells separated by the catalytic membrane. The working solution was circulated through both cells by hydraulic cycles starting and ending in a common reaction vessel. Both halfcells were thermostated which allowed applying a temperature gradient. The reactor was either run under isothermal 
conditions at $25{ }^{\circ} \mathrm{C}$ or a temperature difference of up to $30{ }^{\circ} \mathrm{C}$ between the two half-cells was applied while leaving the average temperature constant at $25^{\circ} \mathrm{C}$. The substrate removal rate increased with increasing temperature gradient. Employing a temperature difference of $30{ }^{\circ} \mathrm{C}$ allowed the removal of $100 \%$ of phenol, 2-/3-/4-chlorophenol, 2,4-dichlorophenol, BPA, and nonylphenol within $30 \mathrm{~min}$. It is unclear whether the environmentally relevant technical mixture or linear isomer of nonylphenol was used. This is of relevance since the linear form of nonylphenol is more prone to oxidation than the branched isomers. The compounds 3methoxyphenol, 4-chloro-3,5-dimethylphenol, 2-benzyl-4chlorophenol, and 4-acetamidophenol were removed by 78 , 62,90 , and $44 \%$, respectively, within 30 min under the same treatment conditions (Georgieva et al. 2010). Consequently, the process was able to remove various phenolic compounds continuously from aqueous solution. It would be worth testing if this process is feasible for treatment of real wastewater. In addition, control experiments using membranes without immobilized enzymes or with inactivated enzymes might be performed, thereby assessing to which extent other processes than laccase-catalyzed transformation contributed to the removal of phenolic compounds. Although the approach looks promising, the long-term enzymatic stability of the laccases on the membrane should be investigated in order to estimate how frequently the membrane has to be replaced and gain herewith preliminary information on the economical relevance of this approach. Moreover, further investigations are needed to state if the application of a temperature gradient is feasible during wastewater treatment regarding cost-efficiency.

A continuously operated fluidized bed reactor was applied in an additional study testing laccase from $T$. versicolor immobilized on polyacrylonitrile beads (Catapane et al. 2013). Aqueous solutions containing different concentrations of nonylphenol and octylphenol ranging from 0.10 to $2.00 \mathrm{mM}$ were recirculated in the reactor and treated with the biocatalysts at $\mathrm{pH} 5$ and $25^{\circ} \mathrm{C}$. As in the study mentioned before, it was not stated whether the author used the environmentally relevant technical mixture or linear isomer of nonylphenol. One hundred percent removal of both compounds after 90 min could be achieved when they were applied at $0.10 \mathrm{mM}$. Control experiments with enzyme-free beads showed that about $5 \%$ of the initially applied substrates were removed in the reactor in the absence of laccase activity. Furthermore, it was shown that the estrogenic activities of the solutions were considerably decreased due to laccase treatment. The stability of the immobilized and dissolved laccase was tested as well in aqueous solution containing $1 \mathrm{mM}$ octylphenol. While the dissolved laccase lost virtually all activity after 50 days of incubation, the immobilized laccase still retained more than $95 \%$ of its initial activity during that time period. After 88 days, the immobilized enzyme still retained around $80 \%$ of its initial activity (Catapane et al.
2013). As in the other studies, no real wastewater conditions were tested. However, the considerable improvement in immobilized enzyme stability compared to the dissolved laccase indicates that the immobilized enzymes might be active over several months, constituting a considerable improvement in process economics.

A procedure for the immobilization of laccase from T. versicolor on chitosan using 1-ethyl-3-(3dimethylaminopropyl) carbodiimide hydrochloride as crosslinking agent was developed, and the resulting biocatalysts were tested for the removal of triclosan (Cabana et al. 2011). In comparison to dissolved laccase, the immobilized enzyme was shown to transform triclosan more efficiently at $\mathrm{pH} 5$ and room temperature. After $6 \mathrm{~h}$ of treatment, $100 \%$ of triclosan (applied at a starting concentration of $17.3 \mu \mathrm{M}$ ) were removed with the immobilized laccase, while $\sim 80 \%$ were removed with dissolved laccase which coincided with a loss in laccase activity. After $6 \mathrm{~h}$, dissolved laccase only retained $55 \%$ of its initial activity. On the other hand, no considerable decrease in activity could be measured for the immobilized enzyme. Furthermore, enzyme immobilization led to increased stability when incubated with chemical denaturants, i.e., $\mathrm{NaN}_{3}, \mathrm{CaCl}_{2}$, $\mathrm{ZnCl}_{2}$, methanol, and acetone, at $\mathrm{pH} 3$ and $20^{\circ} \mathrm{C}$ for $30 \mathrm{~min}$. Regarding organic solvents, the increased stability was attributed to cross-linking of the enzymes leading to increased rigidity. Concerning azide binding and the influence of chaotropic salts, the immobilized enzymes were shown to have increased stability as well (Cabana et al. 2011) which is in contrast to enzymes immobilized as CLEAs (Cabana et al. 2007c).

While the studies summarized in this section demonstrated the general feasibility of EOC transformation by means of immobilized laccases in continuous processes and showed that immobilization in some cases led to a considerable increase of enzymatic stability, they were all carried out under experimental conditions that differ considerably from what can be expected in a real wastewater treatment process. In general, EOC concentrations were applied exceeding environmental concentrations, while process optimizations resulted in unrealistically low $\mathrm{pH}$ and high temperatures. Furthermore, transformations of single compounds were investigated even though it can be expected that EOC transformation depends on the presence of additional compounds (Margot et al. 2013b). Additionally, all studies focused on the removal of EOCs from aqueous solution but lack complete mass balances. Especially, sorption of the investigated EOCs on the carrier materials or reactor walls has not been taken into account in most of the published studies. Consequently, it remains often unclear to what extent EOC removal from aqueous solution was due to actual transformation and to what extent other effects like sorption contributed. Besides applying more application-relevant reaction conditions, studies using radioactively labeled compounds or stable isotopes 
should be conducted in order to unambiguously determine the fate of the investigated EOCs.

\section{Towards application —investigating more realistic treatment conditions}

The laccase-catalyzed transformation of EOCs under realistic conditions needs to be demonstrated before seriously considering laccase treatment as an option for tertiary wastewater treatment. Some recent studies started to do so by applying real WWTP effluents containing realistic EOC concentrations. Reaction conditions and results of these studies are summarized in Table 2.

Complete transformation of a mixture of E1, E2, E3, and EE2 at starting concentrations of $0.4 \mathrm{nM}$ each using laccase of T. versicolor could be achieved in batch reactions at $\mathrm{pH} 7$ and $25{ }^{\circ} \mathrm{C}$ in phosphate buffer as well as in filtered municipal WWTP effluent within $1 \mathrm{~h}$ (Auriol et al. 2007). Addition of $100 \mu \mathrm{M}$ 1-hydroxybenzotriazole as laccase mediator led to improved estrogen transformation. This allowed applying lower enzymatic activities without sacrificing complete estrogen removal within $1 \mathrm{~h}$ (Auriol et al. 2007). In a subsequent study, the same group investigated the effect on the estrogenic activity by means of laccase-catalyzed estrogen transformation in comparison to the effectiveness of an alternative oxidative enzyme, i.e., horseradish peroxidase (Auriol et al. 2008). Both enzymes were capable of completely removing all four estrogens in synthetic water as well as in WWTP effluent, and the estrogenic activity could be removed completely by laccase whereas some still remained using horseradish peroxidase. Consequently, the authors concluded that application of laccases is preferable to horseradish peroxidase for treatment of wastewaters also considering that peroxidases need the addition of $\mathrm{H}_{2} \mathrm{O}_{2}$ (Auriol et al. 2008).

The group of Lema published a plethora of studies focusing on the removal of E1, E2, and EE2 using laccase from M. thermophila (Lloret et al. 2010, 2011, 2012a, b, c, 2013a, b). After first batch tests (Lloret et al. 2010), the laccase was, on the one hand, encapsulated in a sol-gel matrix (Lloret et al. 2011) and applied in a batch stirred tank reactor and, on the other hand, immobilized on Eupergit support (Lloret et al. 2012a, c) for the continuous removal of the EOCs from buffer solutions in a packed bed reactor (Lloret et al. 2012c) and a fluidized bed reactor (Lloret et al. 2012a). The most promising results were achieved in the fluidized bed reactor. Up to $76 \%$ of E1 $\left(11.2 \mathrm{nM} \mathrm{h}^{-1}\right)$ and more than $90 \%$ of E2 $\left(13.4 \mathrm{nM} \mathrm{h}^{-1}\right)$ and EE2 $\left(12.3 \mathrm{nM} \mathrm{h}^{-1}\right)$ could be removed from solutions at $\mathrm{pH} 7,26^{\circ} \mathrm{C}$, a hydraulic residence time of $150 \mathrm{~min}$, and feed addition rates of $14.8,14.7$, and $13.5 \mathrm{nM} \mathrm{h}^{-1}$ for E1, E2, and EE2, respectively (Lloret et al. 2012a). Furthermore, estrogen activity of the effluent was more than $90 \%$ lower compared to the influent at steady-state conditions, showing that EOC removal coincided with water detoxification. This constituted a clear improvement to the previous studies in which estrogen activity was reduced by 63 and $79 \%$ for encapsulated and on Eupergit support-immobilized laccases, respectively (Lloret et al. 2011, 2012c). In the fluidized bed reactor, EOC treatment was performed over 16 days and besides removal rates, stability of the biocatalysts was monitored as well (Lloret et al. 2012a). After 13 days of operation, enzymatic activity of the biocatalysts started to decrease, which was also reflected by a decrease in EOC removal. At day 16, only $46 \%$ of E1 and $70 \%$ of E2 and EE2 were still removed from solution (Lloret et al. 2012a).

In recent studies, laccase was no longer immobilized but used in dissolved form and retained in an enzymatic membrane reactor using an ultrafiltration membrane (Lloret et al. $2012 \mathrm{~b}, 2013 \mathrm{a}, \mathrm{b})$. The authors argue that applying immobilized enzymes has some disadvantages like diffusional limitations of substrates and poses difficulties regarding maintaining constant laccase activities in the reactors. After first tests (Lloret et al. 2012b), process parameters were optimized regarding hydraulic residence time, enzymatic activity, and oxygenation rate using response surface methodology (Lloret et al. 2013a). In the most effective setup, i.e., at a hydraulic residence time of $4 \mathrm{~h}$, an enzymatic activity of $1 \mathrm{kU} \mathrm{L}^{-1}$, and an oxygenation rate of $60 \mathrm{mg} \mathrm{O}_{2} \mathrm{~h}^{-1} \mathrm{~L}^{-1}, 99 \%$ of estrogenic activity could be removed (Lloret et al. 2013a). However, EOC concentrations of the feed were considerably higher than expected in WWTP effluents as can be seen in Table 1. Nevertheless, this was addressed in the most recent study in which the enzymatic membrane reactor was applied for the treatment of real filtered municipal WWTP effluent with real environmental concentrations of E1 (5.62 pM), E2 (1.06 pM), and EE2 (2.50 pM) (Lloret et al. 2013b). E1 was removed by $98 \%$ and E2 and EE2 could no longer be detected after the laccase treatment, indicating that the process effectively transformed the three estrogens since they were not removed in the enzyme-free control (Lloret et al. 2013b). Consequently, these results suggest that treatment of WWTP effluent with laccases under realistic conditions can achieve excellent removal of the three investigated estrogens. However, one of the disadvantages of dissolved enzymes in contrast to immobilized enzymes is the lower enzymatic stability. Therefore, while enzymatic activities remained stable over experiments lasting $100 \mathrm{~h}$, it seems particularly crucial to investigate this over longer time periods in order to gain insights on how frequently enzymes have to be added to the reactor which might be one of the crucial factors concerning costs of the treatment technology.

Additional studies investigated laccase immobilization on silica support material (Demarche et al. 2012; Songulashvili et al. 2012; Nair et al. 2013). Besides batch experiments in buffer solutions, laccase from $C$. polyzona immobilized on mesoporous silica particles was applied to a continuous stirred tank membrane reactor (working volume $50 \mathrm{~mL}$, hydraulic 


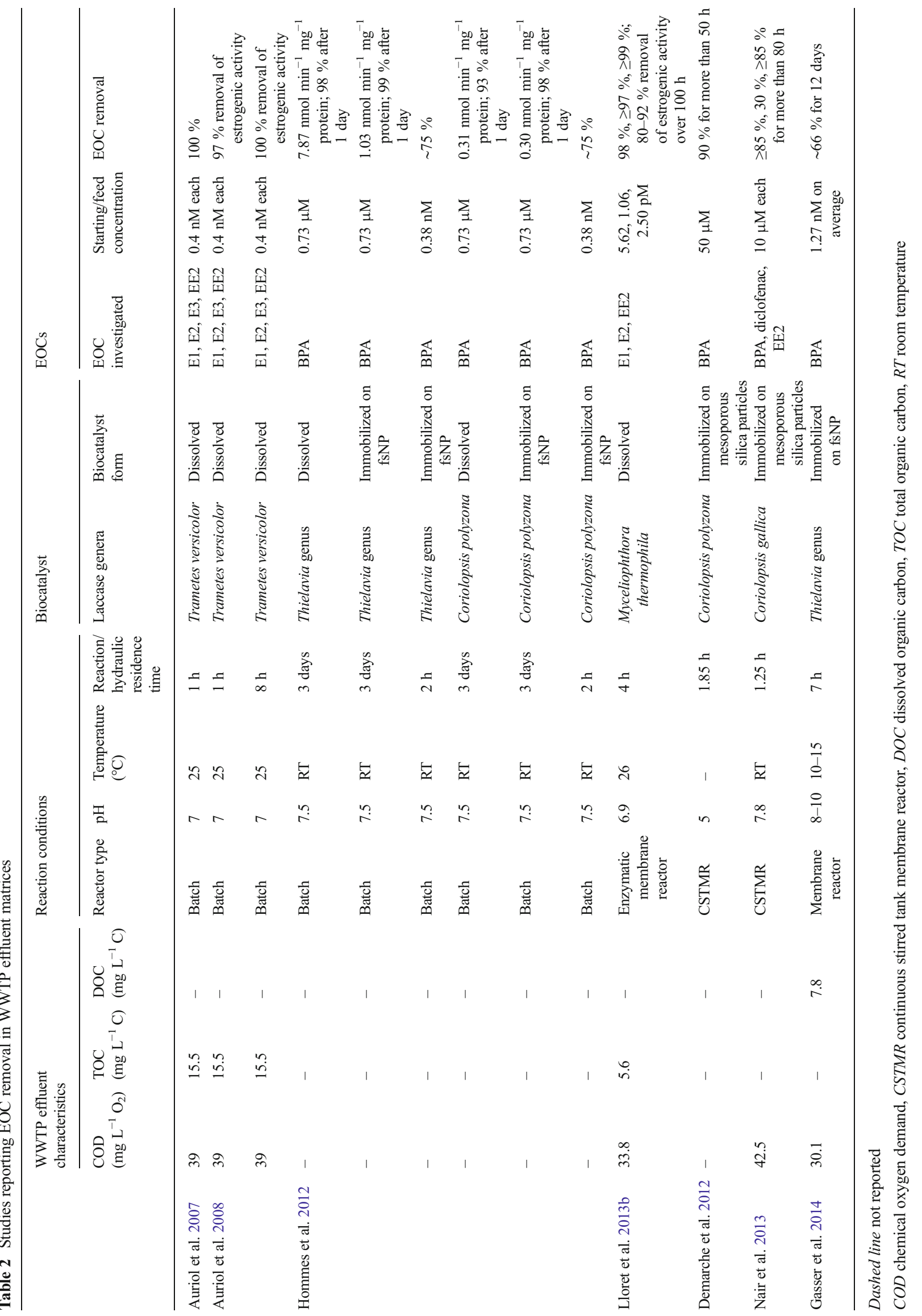


residence time $1.85 \mathrm{~h}$ ) for treatment of WWTP effluent with $\mathrm{pH}$ adjusted to 5 and spiked with BPA for a final concentration of $50 \mu \mathrm{M}$ (Demarche et al. 2012). Ninety percent of BPA could be removed by this system over 30 reactor volumes. Afterwards, BPA removal decreased rapidly which coincided with decreased enzymatic activities, i.e., below $30 \%$ of the initially applied activity, and with partial deposition of the biocatalysts on the top side wall of the reactor (Demarche et al. 2012). Consequently, improvements regarding the stability of the biocatalysts and the mixing of the reactor should be considered in order to increase the durability of the process. Furthermore, it is questionable whether the adjustment of $\mathrm{pH}$ to 5 is economically feasible and environmentally desired in wastewater treatment. Most likely, an additional neutralization step after the enzymatic treatment would become necessary. As in studies discussed before, no data on BPA adsorption on the carrier material is shown. Therefore, it remains unclear to what extent BPA was actually removed through laccasecatalyzed oxidation.

In a further study by the same group, laccase from C. gallica was immobilized on mesoporous silica particles and applied for the treatment of WWTP effluent in the same stirred membrane reactor as used in the previous study (Nair et al. 2013). Concentrations of BPA, EE2, and diclofenac in WWTP effluent were set to $10 \mu \mathrm{M}$ for each compound. This time, the effluent $\mathrm{pH}$ was not adjusted and left at 7.8 and treatment was conducted at room temperature. The experiment was also conducted in buffered solutions at $\mathrm{pH} 5$. Although basically produced by the same method, the immobilized $C$. gallica laccase was considerably more stable than the immobilized $C$. polyzona laccase used in the previous study. Close to $100 \%$ of the enzymatic activity was preserved throughout all the reactor runs each lasting $81.25 \mathrm{~h}$. Since numerous factors differed between the two studies (e.g., wastewater $\mathrm{pH}$, wastewater source, and laccase source), the reason for the apparent increase in stability remains unclear. In

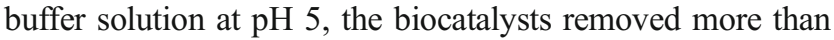
$95 \%$ of BPA and EE2 and more than $70 \%$ of diclofenac over $80 \mathrm{~h}$ in case single compounds were applied. More than $90 \%$ of diclofenac and around $95 \%$ of BPA and EE2 could be removed when all three EOCs were treated as mixture. The increased diclofenac removal in the presence of the other two compounds was most likely due to one or both compounds acting as redox mediator, as discussed above. In wastewater, the biocatalysts were able to degrade more than $85 \%$ of BPA and EE2 and $30 \%$ of diclofenac during $80 \mathrm{~h}$. The considerably lower diclofenac removal in wastewater compared to the buffer solution was attributed, on the one hand, to the higher $\mathrm{pH}$ not satisfying to the conditions of enzyme optimum and, on the other hand, to the presence of organic matter in wastewater (Nair et al. 2013).

Another study optimized the immobilization method described above for the immobilization of enzymes on fsNP
(Zimmermann et al. 2011) regarding consumption of consumables, i.e., APTES, glutaraldehyde, and enzymes (Hommes et al. 2012). Next to laccase from C. polyzona, two additional laccases were immobilized, i.e., from a Thielavia genus and laccase from a Phoma sp. Since the laccase from Phoma sp. was partly inactivated through cross-linking with glutaraldehyde, only the biocatalysts consisting of Thielavia genus and $C$. polyzona laccase were tested in batch reactions for the removal of ${ }^{14} \mathrm{C}$-labeled BPA in buffer solutions and WWTP effluents at $\mathrm{pH} 7.5$ at room temperature. BPA starting concentration was $0.73 \mu \mathrm{M}$, i.e., considerably higher than expected in WWTP effluents, and treatment was monitored over 3 days. As expected, BPA degradation occurred faster in buffer solution compared to WWTP effluent. The biocatalysts containing laccase from the Thielavia genus showed a higher BPA transformation rate in WWTP effluent $(0.14 \pm$

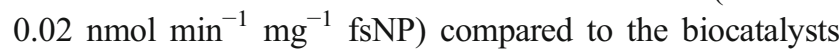
with laccase from C. polyzona $\left(0.10 \pm 0.01 \mathrm{nmol} \mathrm{min}^{-1} \mathrm{mg}^{-1}\right.$ fsNP). BPA concentrations remained stable over 3 days in control experiments applying fsNP with bovine serum albumin immobilized on the surface, indicating that virtually no BPA adsorbed to the particles, as a result of which presumably virtually all BPA removal could be attributed to laccase transformation. Furthermore, BPA degradation in WWTP effluents at environmentally relevant concentrations was investigated, i.e., at $0.38 \mathrm{nM}$. Both biocatalysts removed approximately $75 \%$ of BPA during $2 \mathrm{~h}$ of incubation. The occurrence of a more polar transformation product after treatment with laccase from the Thielavia genus showed that real BPA transformation took place even at such low concentrations (Hommes et al. 2012). The established immobilization method was further optimized for the production of immobilized laccase from the Thielavia genus on fsNP in kilogram scale (Gasser et al. 2014). The produced biocatalysts were subsequently applied in a membrane reactor with a volume of $460 \mathrm{~L}$ in a pilot plant fed with real WWTP effluent. A fixed bed reactor was used prior to the membrane reactor in order to remove suspended solids from the WWTP effluent. Removal of suspended solids was crucial for an efficient treatment process due to several reasons, e.g., EOCs bound to particles are not entirely available for the oxidation by laccase and are therefore not effectively targeted by the treatment technology. Furthermore, sorption and aggregation of the suspended solids with the biocatalysts might severely reduce their catalytic activity while making mixing of the particles considerably more laborious. During the reactor process, the temperature of the effluent was constant between 10 and $15^{\circ} \mathrm{C}$ and the $\mathrm{pH}$ was usually between 8 and 10 . The pilot plant was operated for a total of 43 days. The experiment was conducted in three phases. In the first and third phases, WWTP effluent was treated continuously. In the second phase, lasting from day 19 to day 30, the reactor was operated in batch mode. During the first phase, BPA concentrations in the membrane reactor feed were subjected to 
considerable variations and consequently also varied significantly in the membrane reactor permeate. Laccase activities were also subjected to considerable variations during this first phase most likely due to mixing problems leading to coagulation and sedimentation of the particles. During the third phase, BPA concentrations in the membrane reactor feed were more stable $(1.27 \pm 0.18 \mathrm{nM})$ and it could be shown that they dropped by about $66 \%$ in the permeate $(0.44 \pm 0.13 \mathrm{nM})$. This indicated that laccase treatment led to BPA removal since in a pre-phase without biocatalysts in the membrane reactor no significant differences between BPA concentrations in the membrane reactor feed and permeate were noted. However, adsorption of BPA on the suspended solids that were not removed by the fixed bed reactor or the particles cannot be completely excluded. Laccase activities were also subjected to less variation than during phase 1 . After 43 days, enzymatic activity was $43 \%$ of the initially applied activity, showing that the biocatalysts remained stable over the whole duration of the experiment. In accordance with this pilot-scale experiment, treatment costs were estimated to be $0.130 € \mathrm{~m}^{-3}$ (excluding personnel and maintenance costs) when applying the process for tertiary wastewater treatment at the WWTP at Birsfelden (Switzerland), which treats $28,000 \mathrm{~m}^{3}$ wastewater each day (Gasser et al. 2014). Hence, the costs are slightly above but in the same range as the estimated treatment costs for PAC adsorption and ozonation (also excluding personnel and maintenance costs) for the WWTP at Au (Switzerland, treating $33,000 \mathrm{~m}^{3}$ wastewater per day) which were estimated to be 0.114 and $0.078 € \mathrm{~m}^{-3}$, respectively (Rosenstiel and Ort 2008). However, treatment costs by means of immobilized laccases might be reduced further by optimization of the treatment technology and decreasing biocatalyst production costs (Gasser et al. 2014).

This first test at pilot scale showed promising results by demonstrating EOC removal by laccase treatment under realistic conditions. However, there is still a need for improvement with regard to treatment efficiency. Especially, keeping the particles in suspension and preventing particle aggregation turned out to be of utmost importance. Overall, several parameters can be optimized, i.e., hydraulic residence time, biocatalyst load, and mixing (Gasser et al. 2014). Additionally, monitoring the transformation of more EOCs than just BPA and measuring the effect of laccase treatment on the endocrine activity of the WWTP effluent should also be considered in future studies in order to achieve a more meaningful evaluation of the treatment effectiveness (Gasser et al. 2014).

\section{Towards application — recent approaches for process improvements}

Some recent studies have focused on improving the range of compounds that can be targeted by enzymatic treatments by applying enzyme combinations. The ability of five different laccases to catalyze the oxidation of nine different EOCs was tested in buffer solutions at $\mathrm{pH}$ values ranging from 3 to 7 (Ammann et al. 2014). The tested laccases were from a Thielavia genus, Coriolopsis polyzona, Cerrena unicolor, Pleurotus ostreatus, and Trametes versicolor. The EOCs considered were carbamazepine, diclofenac, sulfamethoxazole, ibuprofen, gemfibrozil, benzophenone-2, benzophenone-4, and BPA. In order to efficiently screen the different combinations, a newly developed method based on oxygen consumption measurements in 96-well plates was employed (Hommes et al. 2013). Based on these screening experiments, two laccases, i.e., from C. polyzona and T. versicolor, were selected for coimmobilization on fsNP in order to produce a biocatalyst with an enhanced substrate range (Ammann et al. 2014). The resulting biocatalyst was able to oxidize gemfibrozil, a compound that could not be oxidized by biocatalysts only containing $T$. versicolor laccase, as well as benzophenone-2, a compound that could not be oxidized by biocatalysts only containing C. polyzona laccase (Ammann et al. 2014).

A further study aiming to increase the substrate range that can be targeted by enzymatic treatment investigated the simultaneous immobilization of a laccase from $T$. versicolor with a versatile peroxidase from Bjerkandera adusta and a glucose oxidase from Aspergillus niger as combined crosslinked enzyme aggregates (combi-CLEA; Touahar et al. 2014). Versatile peroxidases have active sites of manganese peroxidase and lignin peroxidase, i.e., they combine the enzymatic activities of lignin peroxidases and manganese peroxidases (Camarero et al. 1999). Like lignin peroxidases, they have an active site with a high redox potential at low $\mathrm{pH}$ ( $\sim 1.2 \mathrm{~V}$ at $\mathrm{pH} 3$ was estimated for lignin peroxidase), allowing them to oxidize high redox potential substrates like veratryl alcohol (Kersten et al. 1990; Camarero et al. 1999). However, these substances are not effectively oxidized at high $\mathrm{pH}$ values usually found in WWTP effluents since redox potential of the active site decreases drastically with increasing $\mathrm{pH}$ (Wong 2009). Additionally, like manganese peroxidases, versatile peroxidases are able to oxidize $\mathrm{Mn}$ (II) to $\mathrm{Mn}$ (III) (Camarero et al. 1999). $\mathrm{Mn}(\mathrm{III})$ acts subsequently as mediator able to oxidize other compounds (Wong 2009). Hence, versatile peroxidases have potentially a broader substrate range than laccases. However, at $\mathrm{pH}$ values usually encountered in WWTP effluents, it can be expected that versatile peroxidases exhibit virtually no lignin peroxidase activity towards high redox potential substrates. Glucose oxidase was used in the study by Touahar et al. (2014) to provide $\mathrm{H}_{2} \mathrm{O}_{2}$ for the versatile peroxidase. Glucose oxidase produces $\mathrm{H}_{2} \mathrm{O}_{2}$ and concomitantly transforms glucose to gluconic acid (Bankar et al. 2009). The ability of the combi-CLEA to remove EOCs from Milli-Q ultrapure water ( $\mathrm{mLQW}$ ) containing a cocktail of 14 substances, i.e., acetaminophen $(6.6 \mu \mathrm{M})$, naproxen $(4.3 \mu \mathrm{M})$, mefenamic acid $(4.1 \mu \mathrm{M})$, indomethacin $(2.8 \mu \mathrm{M})$, diclofenac 
$(3.4 \mu \mathrm{M})$, ketoprofen $(3.9 \mu \mathrm{M})$, caffeine $(5.1 \mu \mathrm{M})$, diazepam $(3.5 \mu \mathrm{M})$, ciprofloxacin $(3.0 \mu \mathrm{M})$, trimethoprim $(3.4 \mu \mathrm{M})$, fenofibrate $(2.8 \mu \mathrm{M})$, bezafibrate $(2.8 \mu \mathrm{M})$, carbamazepine $(4.2 \mu \mathrm{M})$, and 10,11-epoxy-carbamazepine $(4.0 \mu \mathrm{M})$, was investigated (Touahar et al. 2014). Batch experiments were conducted at $20^{\circ} \mathrm{C}$ and $\mathrm{pH} 5$ for $5 \mathrm{~h}$. The best removals were achieved when glucose $(0.7 \mathrm{mM})$ as well as manganese sulfonate $(7 \mathrm{mM})$ was added at the beginning of the reaction, thus providing the necessary cofactors for the glucose oxidases and versatile peroxidases to express their activities. Removal of several compounds that could not be effectively removed in the absence of glucose and manganese (removal below $20 \%$ ) was considerably increased in their presence, i.e., caffeine (46\% removal), naproxen (45\%), carbamazepine (54\% removal), 10,11-epoxy-carbamazepine (62\% removal), ketoprofen (45\% removal), diazepam ( $45 \%$ removal), trimethoprim ( $57 \%$ removal), fenofibrate ( $71 \%$ removal), and bezafibrate (34\% removal), thus, demonstrating that the substrate range could be increased due to the versatile peroxidase activities. Furthermore, a real wastewater sample was treated with the combi-CLEAs for $5 \mathrm{~h}$ and the removal of the abovementioned EOCs was determined. All compounds were present below the limit of quantification $\left(20 \mathrm{ng} \mathrm{L}^{-1}\right)$ with the exception of acetaminophen which was present at a concentration of $5 \mu \mathrm{g} \mathrm{L}^{-1}$. Acetaminophen was removed by 25 and $12 \%$ with combi-CLEAs and combi-CLEAs in the presence of glucose and manganese sulfate, respectively (Touahar et al. 2014). The authors explain the lower removal by the combiCLEAs in the presence of glucose and manganese with a possible partial inhibition of versatile peroxidase due to the oxidation of a high redox potential compound by manganese as reported before (Jarosz-Wilkołazka et al. 2008). However, in the absence of glucose and manganese, the enzymatic removal of acetaminophen should be mostly catalyzed by laccase since no $\mathrm{H}_{2} \mathrm{O}_{2}$ is produced. Batch experiments of the same study showed that acetaminophen was completely removed by dissolved laccase in batch experiments in $\mathrm{mLQW}$ at pH 5 after $14 \mathrm{~h}$ (Touahar et al. 2014). Therefore, the decrease in removal rather indicates the occurrence of partial laccase inhibition while it is less clear whether versatile peroxidase inhibition takes place.

Results of the studies of Ammann et al. (2014) and Touahar et al. (2014) suggest that a combination of enzymes with different substrate affinities can indeed broaden the range of EOCs that can be targeted in municipal wastewater treatment. However, further studies under more realistic conditions must be conducted to confirm this. Moreover, addition of cofactors like glucose or manganese might necessitate more elaborated process designs and lead to cost increases. Further consideration might also be given to the effects of sugar addition (e.g., glucose) to wastewater effluents, especially regarding possible increases in biomass potentially leading to increased biofouling of membranes.
A different approach to improve EOC removal by enzymatic treatment was taken by another group investigating the effects of a process combining laccase oxidation and GAC adsorption in an enzymatic membrane reactor on the continuous removal of four EOCs, i.e., carbamazepine, diclofenac, sulfamethoxazole, and atrazine (Nguyen et al. 2014). Additionally the effect of syringaldehyde as laccase mediator was investigated. EOC removal was most efficient when laccase, GAC, and a mediator were added. However, toxicity tests showed that wastewater toxicity after treatment was up to six times higher if syringaldehyde was added, thus, demonstrating that while mediator addition might induce improved EOC removal, it can undermine the overall goal of the process, i.e., to decrease wastewater toxicity. The membrane reactor was not operated in the absence of a mediator. However, batch experiments combining GAC and laccase without a mediator were conducted. Notably, the improvement in EOC removal compared to solely enzymatic treatment by combining laccase and GAC in batch experiments was not only due to adsorption on GAC but also due to an increase in enzymatic degradation. The authors propose that coadsorption of enzymes and EOCs on GAC facilitated enzymatic oxidation of the targeted compounds (Nguyen et al. 2014). These results suggest that a combined approach using laccases and activated carbon might be beneficial for EOC removal from wastewaters and merits further investigation.

\section{Conclusions}

Transformation as well as detoxification of a wide range of EOCs using laccases has been demonstrated in a number of studies during the last decade. However, in most cases, reaction conditions were far from those encountered in WWTP effluents. Specifically, high temperatures and EOC concentrations as well as low $\mathrm{pH}$ values were often used, and frequently, only single compounds were investigated. While some studies in recent years started to investigate more realistic conditions using real WWTP effluent and considering continuous processes, there is still a need to demonstrate that laccases can be effectively applied for tertiary wastewater treatment. Many studies only focused on the removal of single or a few compounds from aqueous solution while not investigating the effect on the toxicity of the wastewater. Whereas results of studies investigating reaction products of single compounds suggest that laccase oxidation leads to detoxification of waters, reaction products in more complex mixtures and in real wastewater matrices have to be investigated in the future since the unspecific radical chain reactions that are initiated by laccase-catalyzed oxidation can be expected to lead to different products if different reacting agents are present. Future research should also focus on the effects of laccase treatments 
on EOC concentrations and wastewater toxicity under realistic reaction conditions. Technical description and operation of pilot-scale processes, which consider seasonal variations in WWTP effluents ( $\mathrm{pH}$, temperature, and composition) and recovery of immobilized enzymes, are necessary in order to demonstrate the feasibility of laccase-based tertiary wastewater treatment. This is actually a sine qua non condition to support stakeholders to make decision on the implementation of such a treatment in WWTPs. In this context, it is not only important to demonstrate the feasibility of such a process but also to provide reliable estimations of treatment costs. Those will strongly depend on the costs and the long-term stability of the biocatalysts applied, making solid estimations of production costs and durability indispensable. Otherwise enzymecatalyzed processes for the removal of EOCs run the risk of remaining at lab scale, while competing tertiary treatment options like ozonation or PAC adsorption will be realized.

Acknowledgments The support of the European Commission within the 7th framework program under grant agreement 265946 (MINOTAUR US) and FP7-KBBE-2012-6-311933 (Water4Crops), the Swiss National Science Foundation, National Research Program 66 (Project 4066136686), and the Commission for Technology and Innovation of the Swiss Federal Office for Professional Education and Technology (Grant PFNM-NM 12608.1) is gratefully acknowledged. Special thanks are due to Yannick-Serge Zimmermann (Institute for Ecopreneurship, University of Applied Sciences and Arts Northwestern Switzerland) for the valuable advice.

Conflict of interest The authors confirm that they have no conflict of interests.

\section{References}

Ammann EM, Gasser CA, Hommes G, Corvini PFX (2014) Immobilization of defined laccase combinations for enhanced oxidation of phenolic contaminants. Appl Microbiol Biotechnol 98: 1397-1406

Andreozzi R, Raffaele M, Paxéus N (2003) Pharmaceuticals in STP effluents and their solar photodegradation in aquatic environment. Chemosphere 50:1319-1330

Ashton D, Hilton M, Thomas KV (2004) Investigating the environmental transport of human pharmaceuticals to streams in the United Kingdom. Sci Total Environ 333:167-184

Auriol M, Filali-Meknassi Y, Tyagi RD, Adams CD, Surampalli RY (2006) Endocrine disrupting compounds removal from wastewater, a new challenge. Process Biochem 41:525-539

Auriol M, Filali-Meknassi Y, Tyagi RD, Adams CD (2007) Laccasecatalyzed conversion of natural and synthetic hormones from a municipal wastewater. Water Res 41:3281-3288

Auriol M, Filali-Meknassi Y, Adams CD, Tyagi RD, Noguerol TN, Piña B (2008) Removal of estrogenic activity of natural and synthetic hormones from a municipal wastewater: efficiency of horseradish peroxidase and laccase from Trametes versicolor. Chemosphere 70: $445-452$

Aust SD, Benson JT (1993) The fungus among us - use of white rot fungi to biodegrade environmental pollutants. Environ Health Perspect $101: 232-233$
Ba S, Arsenault A, Hassani T, Jones JP, Cabana H (2013) Laccase immobilization and insolubilization: from fundamentals to applications for the elimination of emerging contaminants in wastewater treatment. Crit Rev Biotechnol 33:404-418

Baldrian P (2006) Fungal laccases - occurrence and properties. FEMS Microbiol Rev 30:215-242

Bankar SB, Bule MV, Singhal RS, Ananthanarayan L (2009) Glucose oxidase - an overview. Biotechnol Adv 27:489-501

Battistuzzi G, Di Rocco G, Leonardi A, Sola M (2003) 1H NMR of native and azide-inhibited laccase from Rhus vernicifera. J Inorg Biochem 96:503-506

Bolz U, Hagenmaier H, Körner W (2001) Phenolic xenoestrogens in surface water, sediments, and sewage sludge from BadenWürttemberg, south-west Germany. Environ Pollut 115:291-301

Boyd GR, Palmeri JM, Zhang S, Grimm DA (2004) Pharmaceuticals and personal care products (PPCPs) and endocrine disrupting chemicals (EDCs) in stormwater canals and Bayou St. John in New Orleans, Louisiana, USA. Sci Total Environ 333:137-148

Brady D, Jordaan J (2009) Advances in enzyme immobilisation. Biotechnol Lett 31:1639-1650

Breen A, Singleton FL (1999) Fungi in lignocellulose breakdown and biopulping. Curr Opin Biotechnol 10:252-258

Brun GL, Bernier M, Losier R, Doe K, Jackman P, Lee HB (2006) Pharmaceutically active compounds in Atlantic Canadian sewage treatment plant effluents and receiving waters, and potential for environmental effects as measured by acute and chronic aquatic toxicity. Environ Toxicol Chem 25:2163-2176

Cabana H, Jiwan JLH, Rozenberg R, Elisashvili V, Penninckx M, Agathos SN, Jones JP (2007a) Elimination of endocrine disrupting chemicals nonylphenol and bisphenol A and personal care product ingredient triclosan using enzyme preparation from the white rot fungus Coriolopsis polyzona. Chemosphere 67:770-778

Cabana H, Jones JP, Agathos SN (2007b) Elimination of endocrine disrupting chemicals using white rot fungi and their lignin modifying enzymes: a review. Eng Life Sci 7:429-456

Cabana H, Jones JP, Agathos SN (2007c) Characterization of cross-linked laccase aggregates and their application to the elimination of endocrine disrupting chemicals. J Biotechnol 132:23-31

Cabana H, Alexandre C, Agathos SN, Jones JP (2009a) Immobilization of laccase from the white rot fungus Coriolopsis polyzona and use of the immobilized biocatalyst for the continuous elimination of endocrine disrupting chemicals. Bioresour Technol 100:3447-3458

Cabana H, Jones JP, Agathos SN (2009b) Utilization of cross-linked laccase aggregates in a perfusion basket reactor for the continuous elimination of endocrine-disrupting chemicals. Biotechnol Bioeng 102:1582-1592

Cabana H, Ahamed A, Leduc R (2011) Conjugation of laccase from the white rot fungus Trametes versicolor to chitosan and its utilization for the elimination of triclosan. Bioresour Technol 102:1656-1662

Camarero S, Sarkar S, Ruiz-Dueñas FJ, Martínez MJ, Martínez ÁT (1999) Description of a versatile peroxidase involved in the natural degradation of lignin that has both manganese peroxidase and lignin peroxidase substrate interaction sites. J Biol Chem 274:10324-10330

Cañas AI, Camarero S (2010) Laccases and their natural mediators: biotechnological tools for sustainable eco-friendly processes. Biotechnol Adv 28:694-705

Castellanos IJ, Cruz G, Crespo R, Griebenow K (2002) Encapsulationinduced aggregation and loss in activity of $\gamma$-chymotrypsin and their prevention. J Control Release 81:307-319

Catapane M, Nicolucci C, Menale C, Mita L, Rossi S, Mita DG, Diano N (2013) Enzymatic removal of estrogenic activity of nonylphenol and octylphenol aqueous solutions by immobilized laccase from Trametes versicolor. J Hazard Mater 248-249:337-346

Cecen F, Aktas Ö (2011) Activated carbon for water and wastewater treatment: integration of adsorption and biological treatment. Weinheim, Wiley VCH 
Cirja M, Ivashechkin P, Schäffer A, Corvini PFX (2008) Factors affecting the removal of organic micropollutants from wastewater in conventional treatment plants (CTP) and membrane bioreactors (MBR). Rev Environ Sci Biotechnol 7:61-78

Claus H (2003) Laccases and their occurrence in prokaryotes. Arch Microbiol 179:145-150

Claus H (2004) Laccases: structure, reactions, distribution. Micron 35: 93-96

Corvini PFX, Shahgaldian P (2010) LANCE: laccase-nanoparticle conjugates for the elimination of micropollutants (endocrine disrupting chemicals) from wastewater in bioreactors. Rev Environ Sci Biotechnol 9:23-27

De Maio A, El-Masry MM, Portaccio M, Diano N, Di Martino S, Mattei A, Bencivenga U, Mita DG (2003) Influence of the spacer length on the activity of enzymes immobilised on nylon/polyGMA membranes: part 1. Isothermal conditions. J Mol Catal B Enzym 21: 239-252

Dec J, Haider K, Bollag JM (2003) Release of substituents from phenolic compounds during oxidative coupling reactions. Chemosphere 52: 549-556

Demarche P, Junghanns C, Mazy N, Agathos SN (2012) Design-ofexperiment strategy for the formulation of laccase biocatalysts and their application to degrade bisphenol A. New Biotechnol 30:96103

Directive 2000/60/EC of the European Parliament and of the Council of 23 October 2000 establishing a framework for community action in the field of water policy. OJ L327:1-72

Directive 2008/105/EC of the European Parliament and of the Council of 16 December 2008 on environmental quality standards in the field of water policy, amending and subsequently repealing Council Directives 82/176/EEC, 83/513/EEC, 84/156/EEC, 84/491/EEC, 86/280/EEC and amending Directive 2000/60/EC of the European Parliament and of the Council. OJ L348:84-97

Durán N, Esposito E (2000) Potential applications of oxidative enzymes and phenoloxidase-like compounds in wastewater and soil treatment: a review. Appl Catal B Environ 28:83-99

Durán N, Rosa MA, D’Annibale A, Gianfreda L (2002) Applications of laccases and tyrosinases (phenoloxidases) immobilized on different supports: a review. Enzym Microb Technol 31:907-931

Escher BI, Baumgartner R, Koller M, Treyer K, Lienert J, McArdell CS (2011) Environmental toxicology and risk assessment of pharmaceuticals from hospital wastewater. Water Res 45:75-92

Fernandez MP, Ikonomou MG, Buchanan I (2007) An assessment of estrogenic organic contaminants in Canadian wastewaters. Sci Total Environ 373:250-269

Fukuda T, Uchida H, Takashima Y, Uwajima T, Kawabata T, Suzuki M (2001) Degradation of bisphenol A by purified laccase from Trametes villosa. Biochem Biophys Res Commun 284:704-706

Fukuda T, Uchida H, Suzuki M, Miyamoto H, Morinaga H, Nawata H, Uwajima T (2004) Transformation products of bisphenol A by a recombinant Trametes villosa laccase and their estrogenic activity. J Chem Technol Biotechnol 79:1212-1218

Galliker P, Hommes G, Schlosser D, Corvini PFX, Shahgaldian P (2010) Laccase-modified silica nanoparticles efficiently catalyze the transformation of phenolic compounds. J Colloid Interface Sci 349:98105

Gasser CA, Hommes G, Schäffer A, Corvini PFX (2012) Multi-catalysis reactions: new prospects and challenges of biotechnology to valorize lignin. Appl Microbiol Biotechnol 95:1115-1134

Gasser CA, Yu L, Svojitka J, Wintgens T, Ammann EM, Shahgaldian P, Corvini PFX, Hommes G (2014) Advanced enzymatic elimination of phenolic contaminants in wastewater: a nano approach at field scale. Appl Microbiol Biotechnol 98:3305-3316

Georgieva S, Godjevargova T, Mita DG, Diano N, Menale C, Nicolucci C, Romano C, Mita L, Golovinsky E (2010) Non-isothermal bioremediation of waters polluted by phenol and some of its derivatives by laccase covalently immobilized on polypropylene membranes. $\mathrm{J}$ Mol Catal B Enzym 66:210-218

Giardina P, Faraco V, Pezzella C, Piscitelli A, Vanhulle S, Sannia G (2010) Laccases: a never-ending story. Cell Mol Life Sci 67:369385

Gómez MJ, Petrovic M, Fernández-Alba AR, Barceló D (2006) Determination of pharmaceuticals of various therapeutic classes by solid-phase extraction and liquid chromatography-tandem mass spectrometry analysis in hospital effluent wastewaters. J Chromatogr A 1114:224-233

González Alonso S, Catalá M, Maroto RR, Gil JLR, de Miguel AG, Valcárcel Y (2010) Pollution by psychoactive pharmaceuticals in the rivers of Madrid metropolitan area (Spain). Environ Int 36:195-201

González S, Petrovic M, Barceló D (2007) Removal of a broad range of surfactants from municipal wastewater - comparison between membrane bioreactor and conventional activated sludge treatment. Chemosphere 67:335-343

Gracia-Lor E, Sancho JV, Serrano R, Hernández F (2012) Occurrence and removal of pharmaceuticals in wastewater treatment plants at the Spanish Mediterranean area of Valencia. Chemosphere 87:453-462

Greim HA (2004) The endocrine and reproductive system: adverse effects of hormonally active substances? Pediatrics 113:1070-1075

Hirsch R, Ternes T, Haberer K, Kratz KL (1999) Occurrence of antibiotics in the aquatic environment. Sci Total Environ 225:109-118

Hommes G, Gasser CA, Howald CBC, Goers R, Schlosser D, Shahgaldian P, Corvini PFX (2012) Production of a robust nanobiocatalyst for municipal wastewater treatment. Bioresour Technol 115:8-15

Hommes G, Gasser CA, Ammann EM, Corvini PFX (2013) Determination of oxidoreductase activity using a high-throughput microplate respiratory measurement. Anal Chem 85:283-291

Hu JY, Aizawa T, Ookubo S (2002) Products of aqueous chlorination of bisphenol A and their estrogenic activity. Environ Sci Technol 36: 1980-1987

Husain Q, Qayyum S (2013) Biological and enzymatic treatment of bisphenol A and other endocrine disrupting compounds: a review. Crit Rev Biotechnol 33:260-292

Iimura Y, Hartikainen P, Tatsumi K (1996) Dechlorination of tetrachloroguaiacol by laccase of white-rot basidiomycete Coriolus versicolor. Appl Microbiol Biotechnol 45:434-439

Jager T (2011) Some good reasons to ban ECx and related concepts in ecotoxicology. Environ Sci Technol 45:8180-8181

Jarosz-Wilkołazka A, Luterek J, Olszewska A (2008) Catalytic activity of versatile peroxidase from Bjerkandera fumosa at different $\mathrm{pH}$. Biocatal Biotransfor 26:280-287

Jin X, Jiang G, Huang G, Liu J, Zhou Q (2004) Determination of 4-tertoctylphenol, 4-nonylphenol and bisphenol A in surface waters from the Haihe River in Tianjin by gas chromatography-mass spectrometry with selected ion monitoring. Chemosphere 56:1113-1119

Jochems P, Satyawali Y, Diels L, Dejonghe W (2011) Enzyme immobilization on/in polymeric membranes: status, challenges and perspectives in biocatalytic membrane reactors (BMRs). Green Chem 13: $1609-1623$

Kandelbauer A, Maute O, Kessler RW, Erlacher A, Gubitz GM (2004) Study of dye decolorization in an immobilized laccase enzymereactor using online spectroscopy. Biotechnol Bioeng 87:552-563

Karthikeyan KG, Meyer MT (2006) Occurrence of antibiotics in wastewater treatment facilities in Wisconsin, USA. Sci Total Environ 361: 196-207

Kasprzyk-Hordern B, Dinsdale RM, Guwy AJ (2009) The removal of pharmaceuticals, personal care products, endocrine disruptors and illicit drugs during wastewater treatment and its impact on the quality of receiving waters. Water Res 43:363-380

Kawai S, Umezawa T, Higuchi T (1988) Degradation mechanisms of phenolic $\beta-1$ lignin substructure model compounds by laccase of Coriolus versicolor. Arch Biochem Biophys 262:99-110 
Kersten PJ, Kalyanaraman B, Hammel KE, Reinhammar B, Kirk TK (1990) Comparison of lignin peroxidase, horseradish peroxidase and laccase in the oxidation of methoxybenzenes. Biochem J 268: 475-480

Kim YJ, Nicell JA (2006) Laccase-catalysed oxidation of aqueous triclosan. J Chem Technol Biotechnol 81:1344-1352

Kim SD, Cho J, Kim IS, Vanderford BJ, Snyder SA (2007) Occurrence and removal of pharmaceuticals and endocrine disruptors in South Korean surface, drinking, and waste waters. Water Res 41:10131021

Klibanov AM, Alberti ED, Morris ED, Felshin ZM (1980) Enzymatic removal of toxic phenols and anilines from waste waters. J Appl Biochem 2:414-421

Korshin GV, Kim J, Gan L (2006) Comparative study of reactions of endocrine disruptors bisphenol A and diethylstilbestrol in electrochemical treatment and chlorination. Water Res 40:1070-1078

Kudanga T, Nyanhongo GS, Guebitz GM, Burton S (2011) Potential applications of laccase-mediated coupling and grafting reactions: a review. Enzym Microb Technol 48:195-208

Kunamneni A, Ballesteros A, Plou FJ, Alcalde M (2007) Fungal laccase - a versatile enzyme for biotechnological applications. In: Méndez-Vilas A (ed) Communicating current research and educational topics and trends in applied microbiology. Formatex, Badajoz, pp 233-245

Kuster M, López de Alda MJ, Hernando MD, Petrovic M, MartínAlonso J, Barceló D (2008) Analysis and occurrence of pharmaceuticals, estrogens, progestogens and polar pesticides in sewage treatment plant effluents, river water and drinking water in the Llobregat river basin (Barcelona, Spain). J Hydrol 358: $112-123$

Laganà A, Bacaloni A, De Leva I, Faberi A, Fago G, Marino A (2004) Analytical methodologies for determining the occurrence of endocrine disrupting chemicals in sewage treatment plants and natural waters. Anal Chim Acta 501:79-88

Lapworth DJ, Baran N, Stuart ME, Ward RS (2012) Emerging organic contaminants in groundwater: a review of sources, fate and occurrence. Environ Pollut 163:287-303

Laskowski R (1995) Some good reasons to ban the use of NOEC, LOEC and related concepts in ecotoxicology. Oikos 73:140-144

Lin AYC, Yu TH, Lin CF (2008) Pharmaceutical contamination in residential, industrial, and agricultural waste streams: risk to aqueous environments in Taiwan. Chemosphere 74:131-141

Lishman L, Smyth SA, Sarafin K, Kleywegt S, Toito J, Peart T, Lee B, Servos M, Beland M, Seto P (2006) Occurrence and reductions of pharmaceuticals and personal care products and estrogens by municipal wastewater treatment plants in Ontario, Canada. Sci Total Environ 367:544-558

Lloret L, Eibes G, Lú-Chau TA, Moreira MT, Feijoo G, Lema JM (2010) Laccase-catalyzed degradation of anti-inflammatories and estrogens. Biochem Eng J 51:124-131

Lloret L, Eibes G, Feijoo G, Moreira MT, Lema JM, Hollmann F (2011) Immobilization of laccase by encapsulation in a sol-gel matrix and its characterization and use for the removal of estrogens. Biotechnol Progress 27:1570-1579

Lloret L, Eibes G, Feijoo G, Moreira MT, Lema JM (2012a) Continuous operation of a fluidized bed reactor for the removal of estrogens by immobilized laccase on Eupergit supports. J Biotechnol 162:404 406

Lloret L, Eibes G, Feijoo G, Moreira MT, Lema JM (2012b) Degradation of estrogens by laccase from Myceliophthora thermophila in fedbatch and enzymatic membrane reactors. J Hazard Mater 213-214: 175-183

Lloret L, Hollmann F, Eibes G, Feijoo G, Moreira MT, Lema JM (2012c) Immobilisation of laccase on Eupergit supports and its application for the removal of endocrine disrupting chemicals in a packed-bed reactor. Biodegradation 23:373-386
Lloret L, Eibes G, Feijoo G, Moreira MT, Lema JM (2013a) Application of response surface methodology to study the removal of estrogens in a laccase-mediated continuous membrane reactor. Biocatal Biotransfor 31:197-207

Lloret L, Eibes G, Moreira MT, Feijoo G, Lema JM (2013b) Removal of estrogenic compounds from filtered secondary wastewater effluent in a continuous enzymatic membrane reactor. Identification of biotransformation products. Environ Sci Technol 47:4536-4543

Lloret L, Eibes G, Moreira MT, Feijoo G, Lema JM (2013c) On the use of a high-redox potential laccase as an alternative for the transformation of non-steroidal anti-inflammatory drugs (NSAIDs). J Mol Catal B Enzym 97:233-242

Loos R, Hanke G, Umlauf G, Eisenreich SJ (2007) LC-MS-MS analysis and occurrence of octyl- and nonylphenol, their ethoxylates and their carboxylates in Belgian and Italian textile industry, waste water treatment plant effluents and surface waters. Chemosphere 66:690699

Loos R, Carvalho R, António DC, Comero S, Locoro G, Tavazzi S, Paracchini B, Ghi-ani M, Lettieri T, Blaha L, Jarosova B, Voorspoels S, Servaes K, Haglund P, Fick J, Lindberg RH, Schwesig D, Gawlik BM (2013) EU-wide monitoring survey on emerging polar organic contaminants in wastewater treatment plant effluents. Water Res 47:6475-6487

Löwenberg J, Zenker A, Baggenstos M, Koch G, Kazner C, Wintgens T (2014) Comparison of two PAC/UF processes for the removal of micropollutants from wastewater treatment plant effluent: process performance and removal efficiency. Water Res 56:26-36

Majeau JA, Brar SK, Tyagi RD (2010) Laccases for removal of recalcitrant and emerging pollutants. Bioresour Technol 101:2331-2350

Maloney SW, Manem J, Mallevialle J, Fiessinge F (1986) Transformation of trace organic compounds in drinking water by enzymic oxidative coupling. Environ Sci Technol 20:249-253

Marco-Urrea E, Pérez-Trujillo M, Cruz-Morató C, Caminal G, Vicent T (2010) Degradation of the drug sodium diclofenac by Trametes versicolor pellets and identification of some intermediates by NMR. J Hazard Mater 176:836-842

Margot J, Kienle C, Magnet A, Weil M, Rossi L, de Alencastro LF, Abegglen C, Thonney D, Chèvre N, Schärer M, Barry DA (2013a) Treatment of micropollutants in municipal wastewater: ozone or powdered activated carbon? Sci Total Environ 461-462:480-498

Margot J, Maillard J, Rossi L, Barry DA, Holliger C (2013b) Influence of treatment conditions on the oxidation of micropollutants by Trametes versicolor laccase. New Biotechnol 30:803-813

Martín J, Camacho-Muñoz D, Santos JL, Aparicio I, Alonso E (2012) Occurrence of pharmaceutical compounds in wastewater and sludge from wastewater treatment plants: removal and ecotoxicological impact of wastewater discharges and sludge disposal. J Hazard Mater 239-240:40-47

Mayer AM, Staples RC (2002) Laccase: new functions for an old enzyme. Phytochemistry 60:551-565

Metcalfe CD, Miao XS, Koenig BG, Struger J (2003) Distribution of acidic and neutral drugs in surface waters near sewage treatment plants in the lower great lakes, Canada. Environ Toxicol Chem 22: 2881-2889

Miao XS, Bishay F, Chen M, Metcalfe CD (2004) Occurrence of antimicrobials in the final effluents of wastewater treatment plants in Canada. Environ Sci Technol 38:3533-3541

Minuth W, Klischies M, Esser K (1978) The phenoloxidases of the ascomycete Podospora anserina. Structural differences between laccases of high and low molecular weight. Eur J Biochem 90:73-82

Mohapatra DP, Brar SK, Tyagi RD, Surampalli RY (2010a) Degradation of endocrine disrupting bisphenol A during pre-treatment and biotransformation of wastewater sludge. Chem Eng J 163:273-283

Mohapatra DP, Brar SK, Tyagi RD, Surampalli RY (2010b) Physicochemical pre-treatment and biotransformation of wastewater and wastewater sludge — fate of bisphenol A. Chemosphere 78:923-941 
Molitoris HP, Van Breemen JFL, Van Bruggen EFJ, Esser K (1972) The phenoloxidase of the ascomycete Podospora anserina X. Electron microscopic studies on the structure of laccases I, II, and III. Biochim Biophys Acta 271:286-291

Morozova O, Shumakovich G, Shleev S, Yaropolov Y (2007) Laccasemediator systems and their applications: a review. Appl Biochem Microbiol 43:523-535

Murugesan K, Chang YY, Kim YM, Jeon JR, Kim EJ, Chang YS (2010) Enhanced transformation of triclosan by laccase in the presence of redox mediators. Water Res 44:298-308

Nair RR, Demarche P, Agathos SN (2013) Formulation and characterization of an immobilized laccase biocatalyst and its application to eliminate organic micropollutants in wastewater. New Biotechnol 30:814-823

Nguyen LN, Hai FI, Price WE, Leusch FDL, Roddick F, Ngo HH, Guo W, Magram SF, Nghiem LD (2014) The effects of mediator and granular activated carbon addition on degradation of trace organic contaminants by an enzymatic membrane reactor. Bioresour Technol 167:169-177

Ostadhadi-Dehkordi S, Tabatabaei-Sameni M, Forootanfar H, Kolahdouz S, Ghazi-Khansari M, Faramarzi MA (2012) Degradation of some benzodiazepines by a laccase-mediated system in aqueous solution. Bioresour Technol 125:344-347

Pal A, Gin KYH, Lin AYC, Reinhard M (2010) Impacts of emerging organic contaminants on freshwater resources: review of recent occurrences, sources, fate and effects. Sci Total Environ 408: 6062-6069

Pierre AC (2004) The sol-gel encapsulation of enzymes. Biocatal Biotransform 22:145-170

Piontek K, Antorini M, Choinowski T (2002) Crystal structure of a laccase from the fungus Trametes versicolor at 1.90- $\AA$ resolution containing a full complement of coppers. J Biol Chem 277:3766337669

Proia L, Osorio V, Soley S, Köck-Schulmeyer M, Pérez S, Barceló D, Romaní AM, Sabater S (2013) Effects of pesticides and pharmaceuticals on biofilms in a highly impacted river. Environ Pollut 178: 220-228

Reinhammar BRM, Vänngåd TI (1971) The electron-accepting sites in Rhus vernicifera laccase as studied by anaerobic oxidationreduction titrations. Eur J Biochem 18:463-468

Rosenstiel R, Ort C (2008) Massnahmen in ARA zur weitergehenden Elimination von Mikroverunreinigungen, Kostenstudie. BAFU, Winterthur

Sánchez-Avila J, Bonet J, Velasco G, Lacorte S (2009) Determination and occurrence of phthalates, alkylphenols, bisphenol A, PBDEs, PCBs and PAHs in an industrial sewage grid discharging to a municipal wastewater treatment plant. Sci Total Environ 407:4157-4167

Santos LHMLM, Gros M, Rodriguez-Mozaz S, Delerue-Matos C, Pena A, Barceló D, Montenegro MCBSM (2013) Contribution of hospital effluents to the load of pharmaceuticals in urban wastewaters: identification of ecologically relevant pharmaceuticals. Sci Total Environ 461-462:302-316

Schwarzenbach RP, Escher BI, Fenner K, Hofstetter TB, Johnson CA, von Gunten U, Wehrli B (2006) The challenge of micropollutants in aquatic systems. Science 313:1072-1077

Sheldon RA (2007) Enzyme immobilization: the quest for optimum performance. Adv Synth Catal 349:1289-1307

Silva BF, Jelic A, López-Serna R, Mozeto AA, Petrovic M, Barceló D (2011) Occurrence and distribution of pharmaceuticals in surface water, suspended solids and sediments of the Ebro river basin, Spain. Chemosphere 85:1331-1339

Snyder SA (2008) Occurrence, treatment, and toxicological relevance of EDCs and pharmaceuticals in water. Ozone Sci Eng 30:65-69

Snyder S, Adham S, Redding AM, Cannon FS, DeCarolis J, Oppenheimer J, Wert EC, Yoon Y (2007) Role of membranes and activated carbon in the removal of endocrine disruptors and pharmaceuticals. Desalination 202:156-181

Solomon EI, Chen P, Metz M, Lee SK, Palmer AE (2001) Oxygen binding, activation, and reduction to water by copper proteins. Angew Chem Int Ed 40:4570-4590

Songulashvili G, Jimenéz-Tobón GA, Jaspers C, Penninckx MJ (2012) Immobilized laccase of Cerrena unicolor for elimination of endocrine disruptor micropollutants. Fungal Biol 116:883-889

Srinivasan C, Dsouza TM, Boominathan K, Reddy CA (1995) Demonstration of laccase in the white rot basidiomycete Phanerochaete chrysosporium BKM-F1767. Appl Environ Microbiol 61:4274-4277

Stasinakis AS, Gatidou G, Mamais D, Thomaidis NS, Lekkas TD (2008) Occurrence and fate of endocrine disrupters in Greek sewage treatment plants. Water Res 42:1796-1804

Strong PJ, Claus H (2011) Laccase: a review of its past and its future in bioremediation. Crit Rev Environ Sci Technol 41:373-434

Ternes TA (1998) Occurrence of drugs in German sewage treatment plants and rivers. Water Res 32:3245-3260

Ternes TA, Stumpf M, Mueller J, Haberer K, Wilken RD, Servos M (1999) Behavior and occurrence of estrogens in municipal sewage treatment plants-I. Investigations in Germany, Canada and Brazil. Sci Total Environ 225:81-90

Thurston CF (1994) The structure and function of fungal laccases. Microbiology 140:19-26

Touahar IE, Haroune L, Ba S, Bellenger JP, Cabana H (2014) Characterization of combined cross-linked enzyme aggregates from laccase, versatile peroxidase and glucose oxidase, and their utilization for the elimination of pharmaceuticals. Sci Total Environ 481: 90-99

Tran NH, Urase T, Kusakabe O (2010) Biodegradation characteristics of pharmaceutical substances by whole fungal culture Trametes versicolor and its laccase. J Water Environ Technol 8:125-140

Tsutsumi Y, Haneda T, Nishida T (2001) Removal of estrogenic activities of bisphenol A and nonylphenol by oxidative enzymes from lignindegrading basidiomycetes. Chemosphere 42:271-276

Uchida H, Fukuda T, Miyamoto H, Kawabata T, Suzuki M, Uwajima T (2001) Polymerization of bisphenol A by purified laccase from Trametes villosa. Biochem Biophys Res Commun 287:355-358

Vethaak AD, Lahr J, Schrap SM, Belfroid AC, Rijs GBJ, Gerritsen A, de Boer J, Bulder AS, Grinwis GCM, Kuiper RV, Legler J, Murk TAJ, Peijnenburg W, Verhaar HJM, de Voogt P (2005) An integrated assessment of estrogenic contamination and biological effects in the aquatic environment of The Netherlands. Chemosphere 59:511-524

Vidal-Dorsch DE, Bay SM, Maruya K, Snyder SA, Trenholm RA, Vanderford BJ (2012) Contaminants of emerging concern in municipal wastewater effluents and marine receiving water. Environ Toxicol Chem 31:2674-2682

Waltman EL, Venables BJ, Waller WT (2006) Triclosan in a north Texas wastewater treatment plant and the influent and effluent of an experimental constructed wetland. Environ Toxicol Chem 25:367-372

Weng SS, Ku KL, Lai HT (2012) The implication of mediators for enhancement of laccase oxidation of sulfonamide antibiotics. Bioresour Technol 113:259-264

Wick A, Fink G, Joss A, Siegrist H, Ternes TA (2009) Fate of beta blockers and psycho-active drugs in conventional wastewater treatment. Water Res 43:1060-1074

Wong D (2009) Structure and action mechanism of ligninolytic enzymes. Appl Biochem Biotechnol 157:174-209

Xu F, Shin W, Brown SH, Wahleithner JA, Sundaram UM, Solomon EI (1996) A study of a series of recombinant fungal laccases and bilirubin oxidase that exhibit significant differences in redox potential, substrate specificity, and stability. Biochim Biophys Acta 1292:303-311

Xu F, Damhus T, Danielsen S, Østergaard LH (2007) Catalytic applications of laccase. In: Schmid RD, Urlacher VB (eds) Modern biooxidation. Wiley VCH, Weinheim, pp 43-75 
Ying GG, Kookana RS (2007) Triclosan in wastewaters and biosolids from Australian wastewater treatment plants. Environ Int 33:199205

Ying GG, Kookana RS, Kumar A, Mortimer M (2009) Occurrence and implications of estrogens and xenoestrogens in sewage effluents and receiving waters from South East Queensland. Sci Total Environ 407:5147-5155

Yuan S, Jiang X, Xia X, Zhang H, Zheng S (2013) Detection, occurrence and fate of 22 psychiatric pharmaceuticals in psychiatric hospital and municipal wastewater treatment plants in Beijing, China. Chemosphere 90:2520-2525

Zhang Z, Feng Y, Gao P, Wang C, Ren N (2011) Occurrence and removal efficiencies of eight EDCs and estrogenicity in a STP. J Environ Monit 13:1366-1373
Zhao JL, Ying GG, Liu YS, Chen F, Yang JF, Wang L (2010a) Occurrence and risks of triclosan and triclocarban in the Pearl River system, South China: from source to the receiving environment. J Hazard Mater 179:215-222

Zhao JL, Ying GG, Liu YS, Chen F, Yang JF, Wang L, Yang XB, Stauber JL, Warne MSJ (2010b) Occurrence and a screening-level risk assessment of human pharmaceuticals in the Pearl River system, South China. Environ Toxicol Chem 29:1377-1384

Zhou Z, Hartmann M (2012) Recent progress in biocatalysis with enzymes immobilized on mesoporous hosts. Top Catal 55: $1081-1100$

Zimmermann YS, Shahgaldian P, Corvini PFX, Hommes G (2011) Sorption-assisted surface conjugation: a way to stabilize laccase enzyme. Appl Microbiol Biotechnol 92:169-178 